\title{
LA ESPADA ROPERA ESPAÑOLA EN LOS SIGLOS XVI Y XVII
}

\author{
POR \\ JOSE MARIA PELAEZ VALLE
}

\section{Consideraciones previas}

SIN entrar en discusiones sobre el origen español de la palabra ropera, parece oportuno aclarar que existe una contradicción entre el ámbito en el que se aplica esta palabra por los eruditos o personas relacionadas con el mundo de la espada - coleccionistas, anticuarios, subastadores, etcétera- y el enclave histórico a que corresponde.

En efecto, todo el mundo admite que en el año 1474 aparece citada por primera vez la palabra rapière, en documentos franceses, y, en España, se encuentra la frase «espada ropera» en la «Relación de los Inventarios que se ficieron en los bienes muebles que tenía el duque Don Alvaro de Zúñiga en 1468 ». Por el contrario, parece ser que se identifica casi en exclusiva la designación ropera -o sus voces homólogas, rapière, rapier, rapieri, etc.- con las espadas de hoja larga y estrecha, sin corte, aptas sólo para esgrima de punta y aplicada casi siempre a espadas con guarnición de lazo o cazoleta, correspondientes a los tipos en boga a partir de mediados del siglo xvi y casi en exclusiva a los del siglo XVII.

Si se piensa en que la evolución de la esgrima no suprime durante bastante tiempo del siglo Xvi la función de corte de la espada, está claro que no deben excluirse de la acepción ropera a las espadas de hoja ancha y de corte, siempre y cuando no tengan simples guarniciones típicamente militares.

Como interesante definición se puede citar la de VAN Vinkeroy en L'art ancien à l'Exposition National Belge (Bruxelles, 1882), que expresa:

«... espada a la española, llamada rapière (ropera), arma a la vez de duelo y de ceñir».

Por tanto, y sin deseos de fijar campos muy estrictos, la significarión que damos a la espada ropera se corresponde con la de una espada que el militar o el civil pueden llevar con el atuendo civil, en parte con fines defensivos $u$ ofensivos y en parte como complemento ornamental del ropaje. 
Aunque específicamente no se identifican como espadas las dagas españolas de mano izquierda, es inadecuado no considerarlas como piezas de acompañamiento de las espadas roperas, con las que frecuentemente se llevaban a juego, o en suite, para su empleo en el tipo de esgrima denominado de «armas dobles», consistente en intentar círculos alrededor del adversario, presentando el frente del cuerpo, y esperando poder efectuar un lanzamiento a fondo simultáneamente con ambos brazos.

Si bien puede estimarse difícil que con esta anticuada esgrima se consiguieran resultados eficaces frente a una escuela de estocadas rápidas, utilizando de perfil las posibilidades de la profundidad máxima de movimientos de brazo y piernas, a pesar de todo las dagas proporcionan una seguridad adicional en ocasiones de peleas con varios contendientes a la vez, o con un contendiente solo, usándolas como medio de desvío de estocadas y cortes.

Por ello, creemos de obligación hacerlas figurar en el artículo, como complemento de la ropera española en el período citado.

El estudio de la espada ropera española se presenta tan particularmente difícil como fascinante.

Las razones de la dificultad son obvias: pocos ejemplares llegados en buen estado hasta nuestros días; dificultad de acceso a las colecciones de los museos, sobre todo para hacer exámenes «en mano»; falta de bibliografía suficiente $y$, salvo el caso de piezas en colecciones privadas accesibles, imposibilidad de efectuar pruebas de reconocimiento por medios tecnológicos, lógicamente muy limitados.

Sorprende que hayan llegado hasta nuestros días menos ejemplares de espadas de los siglos Xvi y xvir que de pintura del mismo período, cuando es evidente que la cantidad de aquéllas tuvo que ser muchísimo mayor.

Como causa de esta situación podemos citar la dificultad de conservación de las armas blancas, su posibilidad de «aprovechamiento» en épocas posteriores, su transformación en piezas utilitarias y el uso de partes, en conjuntos posteriores, que modificaban la estética o las características de la espada.

Por esto último, y debido sobre todo a la legendaria calidad de las hojas de Toledo, muchas espadas del siglo xvil han sido montadas de origen con hojas del siglo Xvi y con guarniciones de época, incluso para formar piezas de alta cualificación.

Otras razones de la escasez de ejemplares son también las devastadoras guerras civiles de nuestro país, épocas en que no han querido conservarse armas, y, desgraciadamente, la no infrecuente falta de respeto hacia el patrimonio histórico y cultural. 
Muy a tener en cuenta en los ejemplares a estudiar es el intercambio comercial internacional del período - máxime teniendo en cuenta la extensión europea del Imperio español-, que permite el montaje, por moda o por prestigio de origen, de hojas de otros países, tanto en España como en el resto de Europa.

Hojas españolas auténticas o falsificadas se encuentran en espadas italianas, alemanas, francesas, inglesas, etc., y es frecuente también la colocación original de hojas alemanas y a veces italianas en espadas españolas, en este caso por razones de precio. En Solingen, por ejemplo, donde en ocasiones trabajan algunos espaderos españoles, existen fabricaciones de serie, de calidad muy aceptable y a precios muy inferiores a los de las hojas españolas (véase reseña comparativa de precios).

En cuanto a algunas guarniciones de alta calidad, se traen ocasionalmente a España, procedentes de Alemania o Italia sobre todo, tipos de gusto renacentista de principios del siglo $\mathrm{xvI}{ }^{1}$.

En España, país acostumbrado en la época a la importación de artículos de ornato y lujo para las clases adineradas, existen mercaderes o comerciantes que facilitan a los gremios la compra de estos elementos y tratan de influir con las gustos extranjeros, no siempre con éxito.

El trasfondo espiritual de austeridad de la corte de los Austrias durante el siglo Xvi influye en la estética del vestido, incluso en la decoración de las espadas, y rara vez se encuentran guarniciones típicas de estilo renacentista, tan en boga sobre todo en Italia.

Solamente se acepta con agrado en el siglo xviI el estilo barroco, a la manera española, nutriéndose, casi en exclusiva, las guarniciones de la extraordinaria - -en calidad- producción española.

En general, y salvo excepciones destinadas a los personajes de la casa real o de la alta nobleza, los diseños se ajustan al gusto español en cuanto a adornos y labrado. Basta una mirada a la iconografía que ilustra los trajes de la corte de los Austrias para comprender que no encajan con los negros ropajes guarniciones ostentosas de espadas.

Los gentileshombres poseen varios ejemplares para combinar con las distintas clases de atuendo.

Son espadas llenas de belleza y funcionalidad en las que el portador suele apoyarse o acariciar el puño con sus guantes perfumados de Ocaña, sintiendo la seguridad que le proporciona y la satisfacción psicológica de la posesión de un arma, cuya calidad y decoración está en consonancia con su poder económico y sus preferencias personales.

' Ejemplo: la espada atribuida a Felipe II. Armería Real G. 48, con hoja toledana ancha, de Juan Martínez de Menchaca (Toledo), de campo llano y filo en bisel con tres estrías caladas en el tercio fuerte. La guarnición de lazo parece obra alemana. 
A partir de principios del siglo Xvir van cambiando las modas del vestir por cierta influencia francesa, sobre todo a mediados de siglo, $\mathrm{y}$ es más frecuente el uso de dorados y plateados. El barroco español incide también en los motivos de decoración (calados, filigranas en las tazas, etc.).

Los sistemas de embellecimiento de las guarniciones son muy diversos. Con mucha frecuencia se emplean técnicas descendientes de las de los artesanos árabes - se sabe que en la época de Abderramán II y Alhaken II existía ya una amplia tradición espadera, principalmente en Toledo- $y$, por tanto, son conocidas por herencia la ataujía y el damasquinado, que utilizan y enseñan los artesanos moros (conversos) que permanecieron en España después de la expulsión de moros y judíos.

A estos conversos pertenece el notable espadero Julián del Rey (Calatayud y Toledo), cuya marca, denominada del «Perrillo» — confundida a veces con el lobo o perro de Passau o Solingen-, está en armas célebres como el Estoque de Justa del emperador Carlos, y también en la espada atribuida a Hernán Cortés, ambas en la Real Armería.

Se emplean también técnicas como el pavonado, nielado, esmaltado, dorado a fuego, plateado, etc., todas sobre labrados previamente forjados, cincelados, etc.

Se tiene referencia de centros espaderos en Toledo, Córdoba, Cuenca, Sigüenza, Cuéllar, Zafra, Badajoz, Calatayud, Valencia, Zaragoza, Valladolid, Sevilla y también en Cataluña. En la zona de Plasencia de las Armas (Guipúzcoa) y en Vizcaya se halla una importante producción armera que, aunque a veces trabaja en espadería, se dedica sobre todo a la fabricación de partes de armaduras, lanzas, picas y a la elaboración de armas de fuego.

Los tratados de esgrima proliferan, y a pesar de ser en muchos casos farragosas descripciones de técnicas intrincadas y de una fantasía alucinante, sobre todo en el siglo XVII, sientan las bases de innovación continuas, recogiendo experiencias que influyen de manera importante en el diseño de las armas.

Algunos libros o escritos creemos que merecen citarse por la fecha de publicación o por su influencia:

1472: La verdadera esgrima y el arte de esgrimir, de Juan Pons (mallorquín),

1474: El manejo de las armas en combate, de Pedro de la Torre (Sevilla).

1512: Ordenanzas para los Maestros de Esgrima, Archivos del Ayuntamiento de Córdoba.

1532: Tratado de la Esgrima, de Francisco Román (sevillano).

1569: Especulación de la Destreza, de Jerónimo de Carranza. 
1600: Libra de las Grandezas de la Espada, de Pacheco de Narváez (Madrid).

1642: Desengaño de la Espada y Norte de Diestros, de Cristóbal de Cala, de Lebrija (publicado en Cádiz).

1672: Filosofía y Matemáticas de las Armas, de Miguel Pérez de Mendoza.

1675: Compendio de los fundamenlos de la verdadera desireza y filosofía de las armas, de Francisco Antonio de Ettenhard y Abarca.

LAS PARTES DE LA ESPADA ROPERA

Se pueden considerar como conjuntos diferenciados esenciales de la espada: la guarnición, cuya misión es proteger la mano y, por tanto, tiene un cometido defensivo, y la hoja, que intervendrá primordialmente en la función de ataques y paradas que la esgrima le confiere.

Para identificar las partes de la espada a que pueden aplicarse, hacemos sobre esquemas un breve recordatorio del vocabulario español que las designa, utilizando modelos que contienen los elementos componentes de la espada ropera.

\section{LAS GUARNICIONES}

Podemos seguir el conjunto de esquemas para contemplar el proceso de la evolución de las formas que adopta la guarnición, y que es impuesto, o al menos influido, por el avance de la esgrima en el tiempo.

Los ejemplares fechados son raros (hablamos de fechas en la guarnición), pero además ello no indica ni que el ejemplar sea un punto de partida de estilo ni que no se trate de un tipo tardío que se construyese bien porque se mantuviera en boga a pesar de haber nacido nuevos diseños, o bien porque no hay que olvidar que la espada era un elemento frecuentemente de encargo, hecho a gusto del propietario y con las características de tipo, medidas, ornamentación, etc., que éste solicitaba.

Un simple ejemplo:

El esquema (fig. U) corresponde a una magnífica espada de Sahagún el Viejo, del que se conocen obras entre 1536 y 1570 , existente en la colección del Instituto Valencia de Don Juan (Madrid), y cuyo tipo de guarnición, con dos cucharas, que puede fecharse hacia 1570 , se sale un poco de los modelos usuales del período, así como la hoja, que es de punta redondeada.

La guarnición está damasquinada en oro y plata y tiene gavilanes en forma de espátula y algo vueltos en sentido contrario (p. 155). 


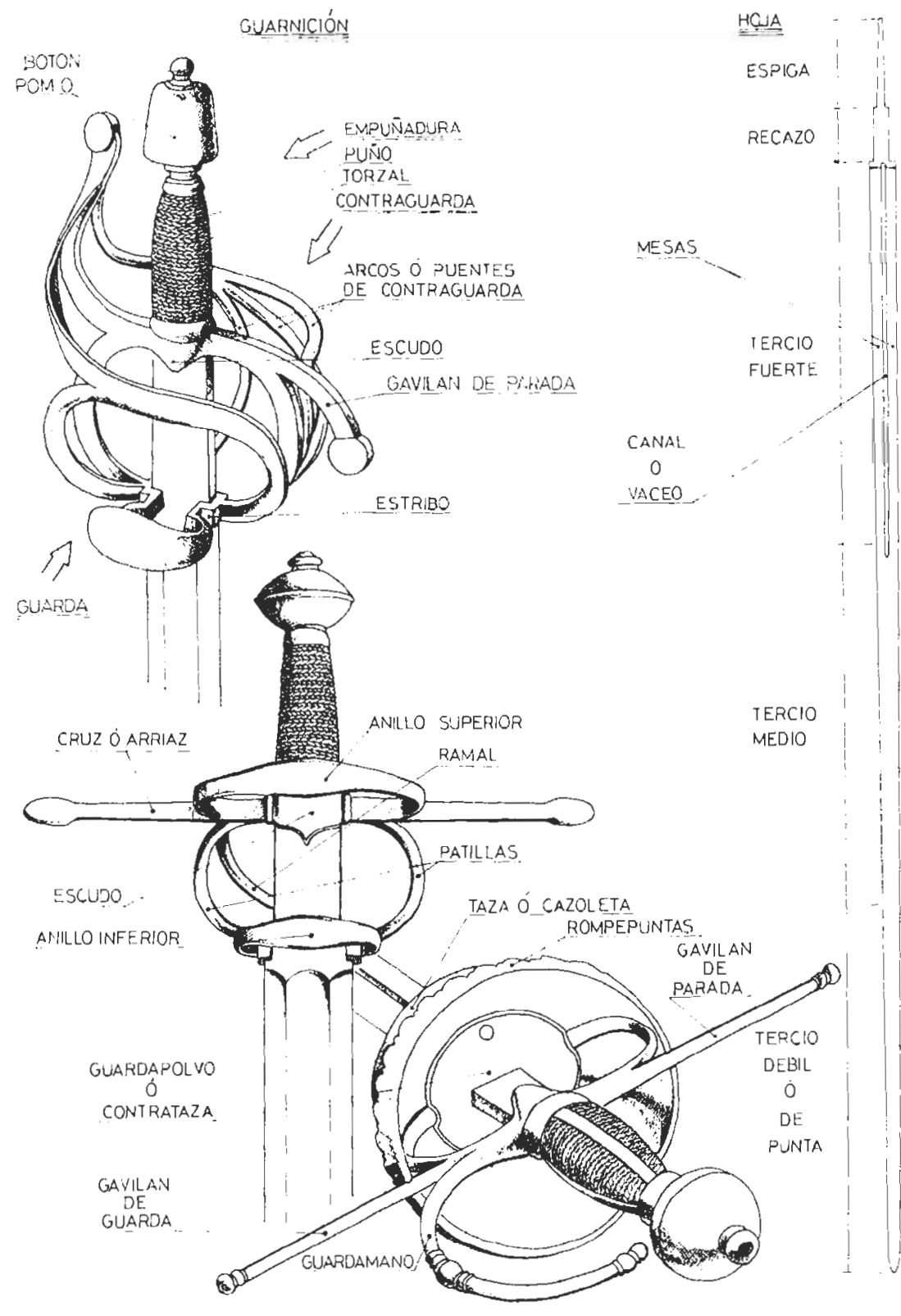


También complica el tema la intercambiabilidad de las hojas, cuyas fechas, cuando existen -insistimos en que son auténticas excepciones las guarniciones fechadas-, no coinciden muy a menudo con la tipología de las guarniciones.

Por todo ello, y para seguir un criterio prudente, hemos preferido designar con intervalos de tercio de siglo la época en que los diseños aparecen con un carácter representativo, es decir, con pujanza, aunque hayan tenido precedentes de aparición en épocas anteriores o subsistan tardíamente.

\section{EvOLUCIÓN DE LAS GUARDAS}

Dentro de la guarnición, se denomina «guarda» la parte de ella que queda del lado del dorso de la mano cuando empuña la espada.

El proceso de cambio anterior al siglo xvi parte de la cruz de arriaz simple y recto (fig. A), que posteriormente curva los brazos ligeramente hacia la hoja (fig. B).

Los pomos son cilíndricos y de gran tamaño y la empuñadura es fuerte y de gran diámetro.

Para asegurar la sujeción de la espada se comienza a pasar el dedo índice sobre la cruz, naciendo para su protección la patilla o gancho (fig. C).

Según el arqueólogo D. Manuel Gómez Moreno, a mediados del siglo xv, y en España, nace la segunda pat11'a, simétrica a la anterior, constituyendo el conjunto denominado en francés pas d'âne (fig. D).

Un ejemplo es la espada G.29 de la Real Armería, de pomo circular de cobre dorado, con dos fachadas, llevando en una la inscripción «Gonzalvi Agidari Victoria de Gallis ad Cannas» y en la otra el escudo de armas de D. Gonzalo Fernández de Córdoba, llamado El Gran Capitán, general de los ejércitos de las campañas de Italia en época de los Reyes Católicos.

El tipo D entra todavía en el siglo XvI.

A finales del siglo Xv o principios del xvi nacen en España los llamados pitones (fig. E), que sobresalen en ángulo recto desde la parte inferior de la patilla, terminados en una pequeña bola, con objeto de proteger la mano del filo de la espada contraria cuando resbala sobre la hoja propia.

Un ejemplo lo constituye la espada G.31 de la Real Armería, atribuida a Fernando el Católico, en cuya hoja se lee en un canal: Antonius me fecit. 
Como elcmento de búsquedas adicionales de protección aparece a principios del siglo xvi el anillo superior colocado sobre el arriaz (fig. G) y desde el gavilán de guarda, en la segunda década del siglo XVI, aunque con antecedentes anteriores, nace un brazo curvo llamado guardamano, que se levanta hasta casi tocar el pomo (fig. H).

A partir de estos modelos base aparecen las modificaciones siguientes reflejadas en los esquemas.

Los brazos del arriaz, en vez de ser rectos, pueden adoptar una forma sigmoidea (fig. I) (primer tercio).

Los pitones se transforman en ganchos planos, ligeramente inclinados hacia arriba (fig. F) (primer tercio).

Paralelo al anillo superior se coloca un nuevo anillo inferior, unido a los dos extremos inferiores de las patillas (figs. J y K) (segundo tercio).

A veces se busca aún mayor protección haciendo unir con una barra puente inclinada el anillo superior y la parte inferior de una patilla, mientras la otra sobresale en pitón o en ganchos (figs. L y M) (segundo tercio).

Una variante de este último tipo, aunque con el gavilán derecho curvado en voluta, sin gavilán izquierdo y con gancho en vez de pitón en la patilla de guarda, es la espada G.49 de la Real Armería, obra de Juan Martínez de Toledo, de estilo renacentista español. Lleva la inscripción: «Para Don Bernardino Suárez de Mendoza, Conde de Coruña».

En el segundo tercio del siglo xvi se anticipa en España la aparición de lazos acestados o en forma de cesta (fig. N), algunos ya muy complicados (fig. O). Es interesante observar la forma de las guardas de la caballería pesada, que aparecen en los tapices de la Sala de las Batallas del Escorial, representando la batalla de San Quintín, en 1557, y aunque evidentemente se trate de espadas militares, demuestra su existencia en espadas roperas.

En el último tercio el guardamanos se refuerza con dos brazos que suben, por un lado de la guarda, desde el anillo superior cerrado o abierto, y por el otro con el final de la contraguarda, que al bajar se divide a su vez en dos o tres ramales (fig. G1 de las contraguardas y $P$ de las guardas).

Es frecuente que se suprima el gavilán de guarda y el de parada sea de forma curvada hacia la hoja.

La extendida costumbre de la esgrima de punta hace colocar en ocasiones placas perforadas en el anillo inferior, precediendo a las importantes modificaciones de forma del siglo XviI.

Los tipos de lazo descritos para el segundo y tercer tercio entran en el siglo xviı con una estructura simplificada y de gran elegancia. 

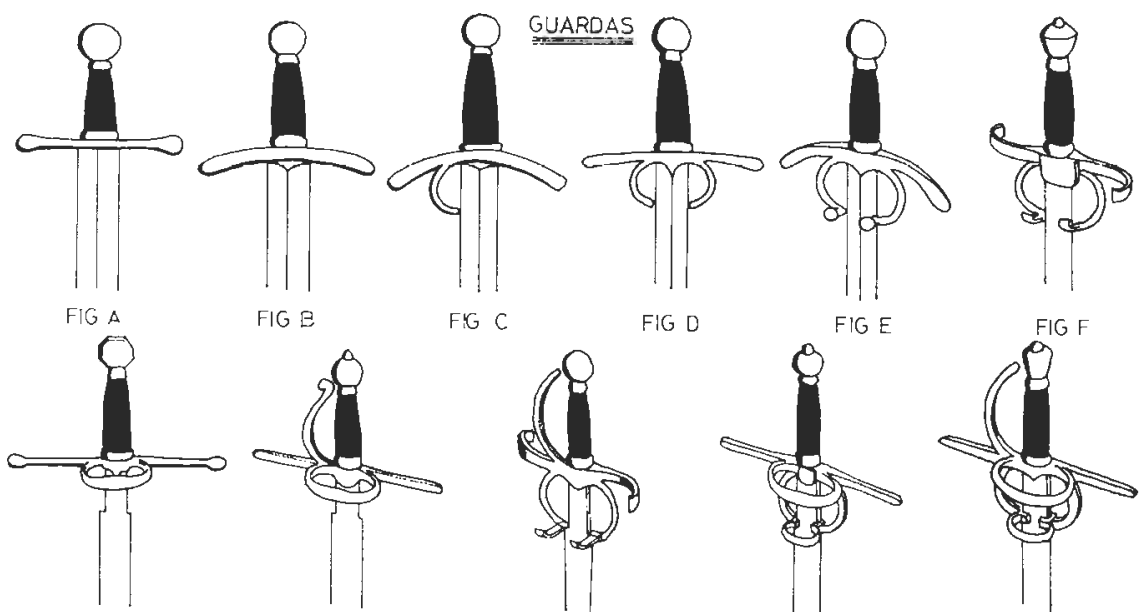

FIG E

$F G C$
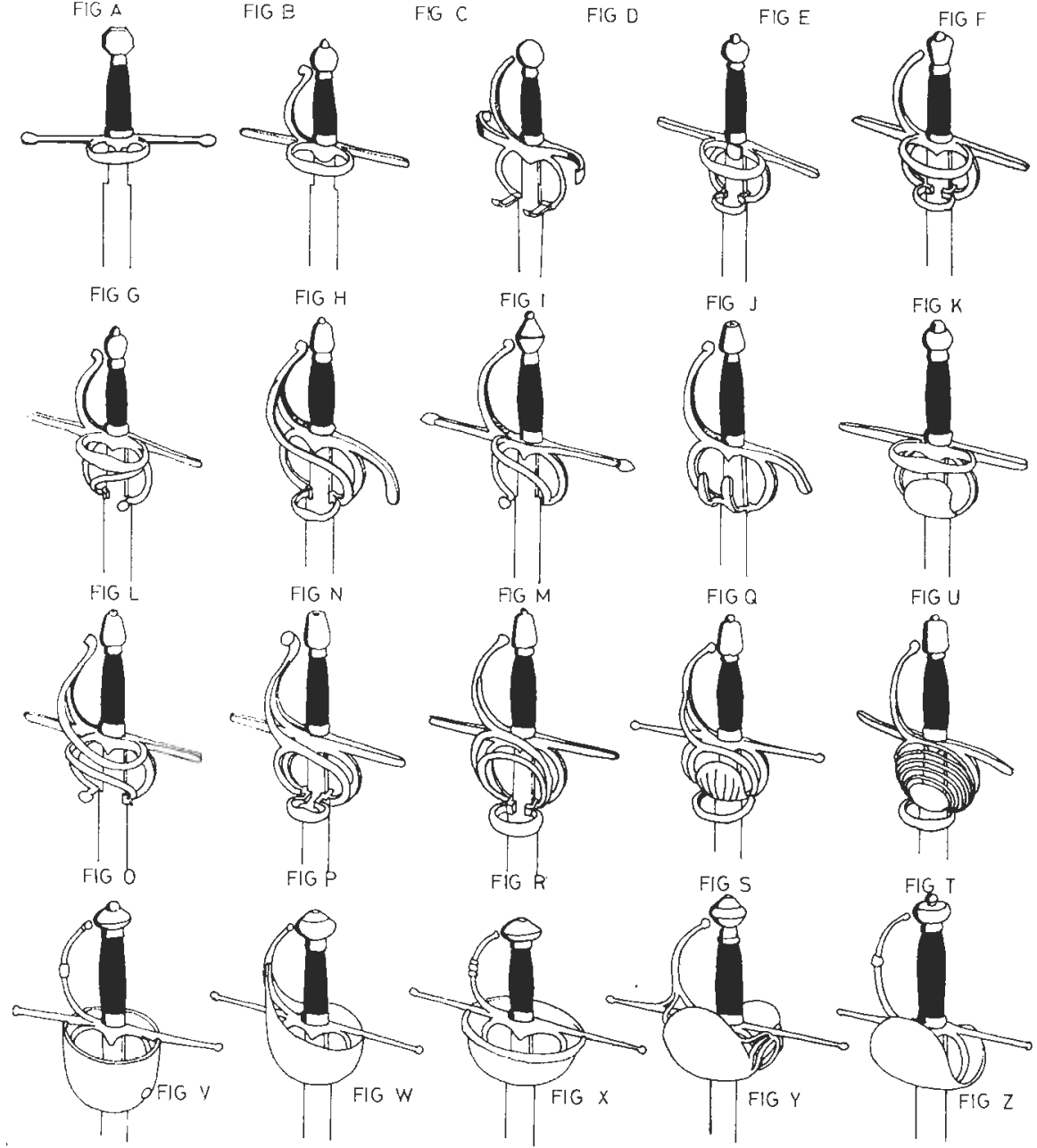
Los tipos $Q$ y $R$ se prodigan a comienzos del siglo xvil y en definitiva constituyen pasos avanzados, cada vez más, en busca de una protección más completa de la mano, como los que incluyen veneras o conchas (fig. S), o auténticas cazoletas en «esqueleto» como el tipo T. Todos ellos se pueden encontrar en el primer tercio del siglo xvir.

La guarnición cerrada, denominada en España de «cazoleta», en diversas variantes, coexiste con los tipos anteriores a principio de siglo y perdura durante todo el siglo xvi (figs. $\mathrm{X}, \mathrm{V}$ y W), llegando a principios del siglo xvin (Retrato de Felipe $V$ de Anjou, por Rigaud).

En el segundo tercio del siglo XvIr, con algunos precedentes, se prodiga también que la guarda y la contraguarda estén formadas por dos conchas, que forman un volumen algo menor que el semiesférico de la taza, y que se unen por los laterales mediante lazos y alambre, tipos $Y-Z$, que en el tipo $Y$ llegan a unirse a los gavilanes.

En todo el siglo es característica peculiar de la espada ropera española de cazoleta o conchas la extraordinaria longitud de los gavilanes. El borde de las tazas se curva a veces hacia fuera, constituyendo un reborde llamado rompepuntas, cuya finalidad es quebrar o enganchar la punta de la espada contraria.

Capítulo aparte merecen las espadas de cazoleta, que en todo el mundo hicieron reconocer la maestría de los armeros españoles, singularmente los de Toledo. Con dibujos y calados, a veces de auténtico encaje, grabados al ácido, plateados o dorados, con gavilanes y guardas torcidas, frecuentemente en espiral, constituyen un conjunto de estética fascinante y evocadora de los gustos artísticos del período, que si estuvo lleno de desgracias y descalabros de guerra, no en vano se llamó Siglo de Oro por la pujanza y esplendor artístico.

Los calados no solamente tienen un objeto ornamental; sus huecos, formados por bellas figuras o motivos florales, son además una trampa mortal para sujetar o partir la extremidad de la punta de la espada enemiga.

En el interior de las tazas se coloca, muchas veces sujeta por las patillas que subsisten, una pieza denominada contrataza o guardapolvo, que en los ejemplares más ricos está también calada a juego con los dibujos de la taza. A nuestro juicio, aunque se admita generalmente el nombre, debería denominarse contrataza y dejar el nombre de guardapolvo para la pieza de cuero que «cierra» el final del recazo con la abertura inferior de la taza, siendo éste el significado usual de la palabra en espadas de época posterior. 


\section{LAS CONTRAGUARDAS}

Comienzan en el siglo xvi con una barra curva que, saliendo de la parte inferior de la patilla de guarda, va hasta el gavilán de parada (fig. A1) o bien uniendo mediante un anillo las partes inferiores de las patillas (figs. B1 y $\mathrm{Cl}$ ).

En el segundo tercio del siglo xvi la contraguarda se forma o por un solo ramal curvo (fig. D1) o por el desdoblamiento de este ramal de manera que, saliendo del gavilán de guarda, se divide en dos o tres brazos que van, en forma curvada, hacia las partes inferiores de las patillas (fig. D1, E1 y F1).

Desde la segunda mitad del siglo xvi hasta el final del mismo, la contraguarda eleva sus ramales hasta el guardamano (fig. G1).

En el siglo xviI las contraguardas del segundo y tercer tercio del siglo anterior se mantienen simplificadas y aparecen tipos como el H1, que van constituyendo con variantes (I1) el paso hacia la semiesfera o cazoleta.

En las variantes de la cazoleta o guarnición de conchas, la guarda y contraguarda formarán lógicamente el mismo cuerpo y serán simétricas con respecto al plano de la hoja.

\section{Los PUÑOS}

Los puños varían también con la esgrima. En la espada de corte son naturalmente más gruesos y de mayor sección en la parte más próxima a los gavilanes. Conforme cambia la técnica de la esgrima, al mayor cmpleo de la punta se hacen más cortos, ya que al pasar siempre el dedo índice por encima de la cruz, la longitud puede ser menor.

Corrientemente se recubre la madera que rodea la espiga con hilos de hierro o de cobre, en los ejemplares de alta calidad de oro o plata y excepcionalmente de seda. Con todos estos materiales se elaboran a veces torzales que se pueden alternar con vueltas de hilo simple para embellecer el cfecto de la empuñadura y favorecer su agarre. Se suelen hacer también puños con maderas exóticas talladas en forma de gajos, cuyo grueso de sección poligonal desciende en curva desde el centro del puño hacia las puntas.

Para algunas espadas de cazoleta del segundo tercio del siglo xvir se fabrican bellísimos ejemplares de puños labrados en hierro y cincelados formando dibujos calados. Otras veces el puño de hierro presenta resaltes en talla de diamante o pequeñas pirámides cuadrangulares. 


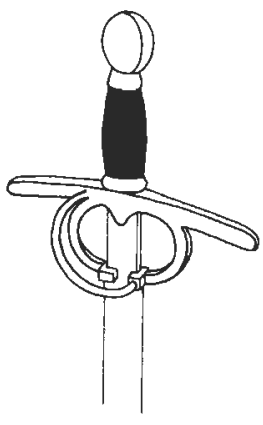

$F \mid G \cdot A_{1}$

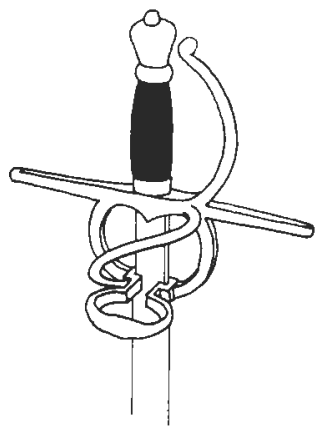

FiG. D

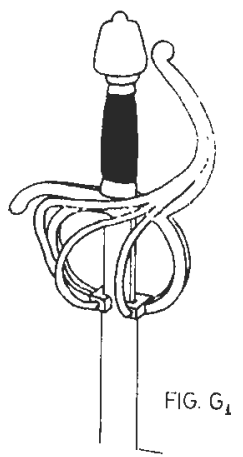

\section{CONTRAGUARDAS}

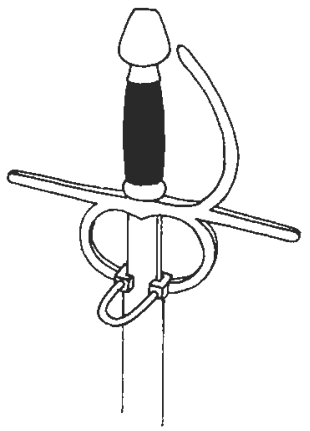

$F \mid G . B$,

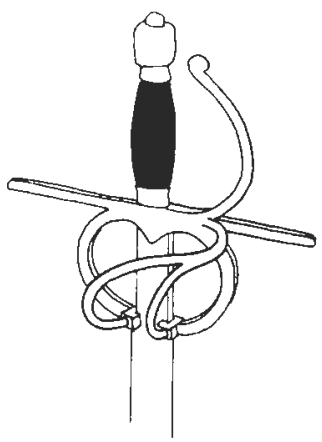

$F I G . E_{1}$

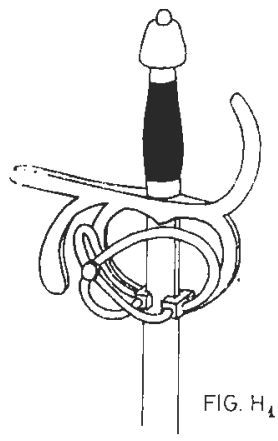

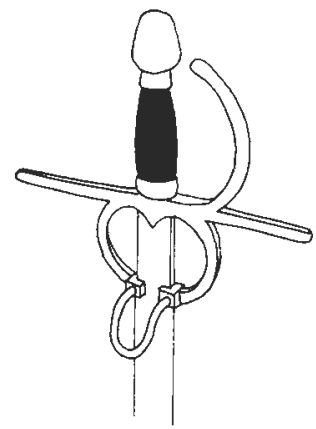

FIG $C_{1}$

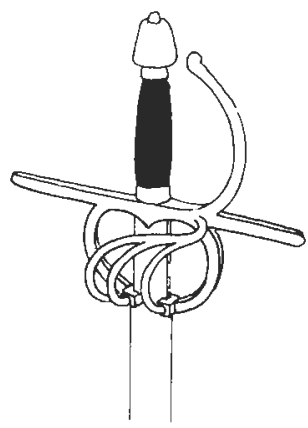

FIG. $F_{1}$

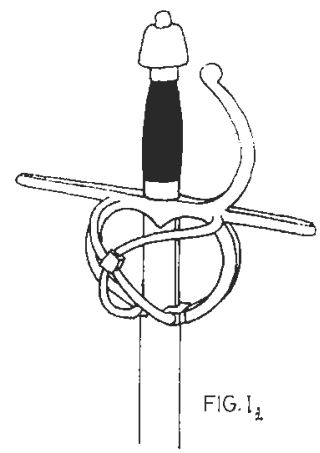


Los pomos comienzan en el siglo Xvi heredando la forma de épocas anteriores, es decir, cilíndrica, y se van transformando en lenticular o en forma de veneras cerradas, para llegar a ser en el segundo tercio del siglo xvi de forma periforme invertida, esférica u ovoidal. Igualmente se construyen caprichosas formas prismáticas combinadas. Por ejemplo, base o zona inferior prismática y remate piramidal.

Es característico del trabajo español de pomos formados por dos o cuatro cuerpos, en ángulo recto, perforados con agujeros cilíndricos o de dibujo irregular.

En el último tercio del siglo xvi aparece la forma troncocónica con estrías, según la generatriz, o en forma helicoidal. Posteriormente se construyen de forma troncocónica, viéndolos en el plano de la hoja y de sección con espesor decreciente hacia el botón.

En los finales del siglo xvi y durante todo el siglo xvil predominan los pomos en forma esférica, achatada por los polos, con dibujos muy variables, según la ornamentación.

EI pomo es una parte esencial de la espada al servicio del contrapeso para conseguir el «balance» que sitúa el centro de gravedad de la espada de tal manera que, quedando a una media cuarta de la guarnición, garantiza una alta manejabilidad de la espada.

Los ejemplares de taza del siglo XvII, con todas las partes originales, tienen un balance extraordinario, a pesar de la gran longitud que tienen algunas hojas.

\section{LA GUARNICIÓN EN LAS DAGAS}

Las dagas de mano izquierda, si bien cuentan con antecedentes previos a la primera mitad del siglo xvi, siempre a juego con el diseño de la espada, se prodigan a partir de principios del siglo xvir, y ya en el primer tercio aparecen en su auténtica versión española, denominada de vela por su semejanza con una vela marina triangular.

De su forma nace también la acepción guardamanos por la protección que ofrecen a la mano izquierda, que rodea el puño por el interior de la guarda y se afianza pasando el dedo pulgar por encima de los gavilanes, asentándolo sobre un alojamiento ovoidal de la hoja en el recazo, que aquí queda exterior a la cruz.

De los gavilanes, siempre de gran longitud, salen en algunos ejemplares dos «cuernos» o barras paralelas al recazo, para poder servir también de «atrapahojas». 
Los gavilanes pueden emplearse para aprisionar la hoja de la espada contrincante sujetándola entre el recazo u hoja y uno de sus largos brazos. A esta operación se denomina «engavilanar».

Los dibujos y diseño de las dagas siempre están en suite con la espada, a la que acompañan incluso cuando el uso de la daga ha sido superado con la eficaz esgrima de las espadas de taza con hoja de verduguillo.

Las dagas de vela suelen presentar también el rompepuntas o doblez que envuelve los bordes del guardamano, cuya función es idéntica que la de la espada.

Las dagas, como las espadas, sólo en contados casos poseen marcas en la guarnición, estando situadas entonces, casi siempre en la cruz, en lugares próximos al puño.

\section{LAS HOJAS}

Una clasificación inicial de las hojas, obedeciendo al tipo de esgrima que iban a utilizar, permite diferenciar las de corte y punta y las que sólo emplean la punta, por lo que, consiguientemente, no precisan un filo cortante.

Es conveniente tener en cuenta que la forma de las hojas sirve de base en muchos casos para denominar las espadas con una clasificación de uso generalizado, aunque la termínología no diferencia claramente los tipos, y para mayor complicación se han empleado con frecuencia términos erróneos o inadecuados. (Es interesante el libro de Leguina Glosario de voces de Armería, así como el de Maestros Espaderos - Sevilla, 1897 - del mismo autor.)

Como aclaración de expresiones que aparecen confusamente empleadas creemos de interés citar algunas acepciones de espadas a las que la forma de la hoja les da nombre.

Estoque (según Leguina): «Espada con hoja angosta de cuatro lados, que se juega siempre de punta,» Tapia y Salcedo aclara: «Los había de cinco palmos como las espadas, aunque por lo general eran más largos.»

En concreto, el estoque es un arma para uso de punta, aunque por extensión se ha denominado estoque a espadas de presentación, con hojas anchas, que eran objeto de regalo a personajes, y que se empleaban en ceremonias. Un ejemplar notable es el Estoque del Conde de Tendilla, que le fue regalado por el Papa Inocencio VIII, actualmente en el $\mathrm{Mu}$ seo Lázaro Galdiano. 
En el siglo Xvil se emplea el nombre de estoque, o antecediendo esta palabra al tipo de guarnición - por ejemplo, estoque de cazoleta-, para describir una espada de hoja estrecha con bordes no cortantes, apta para ser empleada en acciones finales de punta.

Las espadas llamadas verdugos o verduguillos tienen una hoja del grosor de un dedo meñique - según Leguina-, generalmente de sección rectangular, cuadrada o triangular, muy flexible y elástica.

Espadas de hoja flamígera son aquellas que tienen hojas con bordes curvos, en forma sinusoidal y ondulada, cuyds líneas confluyen en la punta.

Las hojas denominadas en francés colichemarde, cuyo primer tercio o tercio fuerte es ancho y se adelgazan bruscamente en forma de estoque, son escasas en España. Hizo alguna el maestro Pedro del Monte, de Toledo, y el célebre Tomás de Ayala.

A principios del siglo XvI las hojas de ropera son anchas, y conforme se va transformando la esgrima de corte a la de punta, se estrechan y alargan. A finales del siglo xvi o principios del siglo xvir las hojas se alargan extraordinariamente, y a pesar de que una excesiva longitud no es eficaz en buena técnica, se encuentran ejemplares incluso de más de $1,1 \mathrm{~m}$, muchas veces con guarnición de taza. A mediados del siglo Xvir vuelven de nuevo las hojas anchas, que conviven con hojas finas, pero todas de un largo de $85-95 \mathrm{~cm}$. La hoja ancha persistirá en los finales del siglo XviI hasta su uso en espadas de caballería en el siglo XVIII.

Algunas normas oficiales limitan el largo de las espadas.

Hay edictos de Felipe II en 1558-1564 y 1566. En el de 1558 se dice: «Ninguna persona sea osada de traer verdugos, estoques ni espadas de más de cinco cuartas de cuchilla en largo, ni lleve daga, ni puñal, si no lleva espada.» De este edicto se desprende la existencia común del verdugo y el empleo ya de las dagas de mano izquierda.

Todas estas normas se contravienen con frecuencia. Los espadachines o «matasietes» obligan a pendencias y a tener que «tirar de la blanca» - expresión populachera- para defenderse. Los pendencieros de ventaja llevan a veces pavonada la punta de la espada para que el contrincante, en lances nocturnos, calcule mal el largo de la espada, al ver sólo el brillo en parte de la hoja.

En ejercícios de esgrima se usaban las espadas denominadas mulatas, negras de guarnición y hoja, terminadas en un botón. También se construían hojas extraordinariamente largas, hasta de 1,4 m., que eran usadas por los maestros de esgrima para separar a los contrincantes acalorados, acción llamada «echar el montante» o «meter el montante».

Atención especial merece la fabricación de las hojas. Las ferrerías de Vizcaya o Guipúzcoa elaboraban con mineral, procedente de Vizcaya o 
Mondiagón, los hierros pudelados ${ }^{2}$, que fabricaban por el sistema de descarburar directamente el mineral, con carbón vegetal, y obtener masas o bolas, que se martillan hasta conseguir primitivos perfiles.

La conservación de documentos de la época permite conocer que los procesos tenían un grado de mecanización rudimentaria, utilizando martillos accionados hidráulicamente.

Este material, sometido a veces (según normas oficiales a lo largo del período) a un control administrativo y técnico por los «veedores» o controladores reales, es comprado por los gremios espaderos.

Tengamos en cuenta que el procedimiento de obtención de hierros por fusión, por un sistema parecido en versión primitiva en un alto horno, no comienza hasta 1620, con el establecimiento de hornos en Liébanes y La Cabada (Santander), por un industrial de los Países Bajos, y este hierro, por disposición real, sólo se emplea para la fabricación de cañones.

El proceso de forja de las hojas «a la española» es complejo y extraordinariamente difícil, tanto por la ejecución como por las exigencias de las pruebas a que éstas se deben someter.

Con operaciones iniciales de forja, y en el taller de los espaderos, se obtienen dos materiales distintos: un acero o hierro dulce para el interior o núcleo de la hoja y un acero de mayor porcentaje en carbono, que rodeará a este núcleo interno mediante la colocación de dos láminas o «tejas» exteriores a cada lado del núcleo y cubriendo en exceso los bordes

La unión en caliente se realiza por martillado progresivo de punta a cabeza y en el sentido del ancho de centro a bordes. La operación de comienzo de unión de los materiales en la punta se denomina «dar la puntada».

Cualquier fisura interna, insistencia excesiva del martillado en una zona, oxidaciones, inclusiones de carbón u otros eventos puede estropear un trabajo tan costoso. Hay disposiciones oficiales que prohíben la existencia de grietas, que en lenguaje de la época se llaman «fortalezas».

Conseguida la hoja de forma en bruto, se labran por caldas y operaciones sucesivas de forja las distintas partes según el diseño, se «echan las mesas» o planos de la hoja, se forman bordes y punta y se hacen los vaceos.

La operación de temple es un auténtico secreto transmitido de generación en generación y relacionado con una mítica que abarca desde supersticiones de denominación de los colores de caldas hasta pronun-

2 Pudelados: esta palabra es, naturalmente, posterior, puesto que se deriva de la inglesa puddle, pero la citamos para que se interprete el producto férreo obtenido. 
ciar sortilegios secretos durante la inmersión en agua, rezar oraciones y utilizar, en definitiva, procedimientos que suponían un cierto control de la temperatura y de la velocidad de temple para alcanzar una estructura que hoy se denominaría, metalúrgicamente hablando, como martensítica, estructura que produce un incremento notable de dureza y resistencia, pero con alto grado de fragilidad.

Otro tratamiento posterior de calentamiento lento a baja temperatura, que denominaríamos hoy revenido, disminuía los efectos del temple hasta conseguir una estructura homogénea, con buena dureza y resistencia y adecuado comportamiento a la fragilidad. Los enfriamientos al aire se acompañaban de pasadas de «grasa o riñonada de carnero».

El resultdo es altamente espectacular. El núcleo maleable y resistente confiere elasticidad y soporta una cubierta exterior de alta dureza y resistencia.

Sólo artesanos perfectamente capaces y conocedores de secretos con antecedentes perdidos en la historia pueden conseguir unas hojas cuya fama ya tiene reputación mundial, y que se someten a pruebas tan espectaculares como las que se relatan.

Estas pruebas equivalen a lo que constituiría hoy un conjunto de ensayos físico-mecánicos de flexión, plegado, torsión, resistencia al choque, etc.

El comportamiento a la flexión se comprueba por la posibilidad de adaptación a la curva de una muletilla de cuero, hasta que después de adoptar la curva, quedan dos ramales paralelos. Se denomina en el argot de espaderos «prueba de la muletilla». Que estas pruebas y cualidades no debían de ser desconocidas en otros países lo prueba la cita de William Shakespeare, que dice en Las alegres comadres de Windsor: «Estar como hoja de Toledo arrollada con la punta junto a la guarnición.»

La resistencia a la torsión se verifica sujetando la punta en plomo y girando la parte superior alrededor de un eje imaginario, a lo largo de la hoja, hasta alcanzar un giro de 180 grados.

La prueba de la $\mathrm{S}$ consiste en curvar la mitad de la longitud en semicírculo y, apoyando la hoja en su mitad, conseguir formar una figura en $S$, curvando en sentido contrario la mitad restante.

Ensayados los aspectos anteriores, y una vez acabado el trabajo, se descarga un fuerte tajo de filo sobre un casco de acero, no debiendo producirse mellas ni roturas.

No es difícil imaginar que con tales pruebas las hojas españolas gozaran de merecido renombre.

Manufactura distinta tienen las hojas de las dagas de mano izquierda, ya que su finalidad es fundamentalmente resistir el impacto de golpes o cortes. 
El proceso es parecido - no se introduce el núcleo de hierro dulce-, la composición es homogénea, y aunque también el acero sufre temple y revenido, se persigue conseguir una hoja más dura, más resistente - tiende menos a la fragilidad al ser de menor longitud - y la hoja es más «acerada».

El borde se suele terminar en forma de sierra, con dentados y perfiles, entrantes y salientes, para, con una técnica de diseño que combina estética e imaginación de formas, dañar, sujetar o partir la hoja de la espada del contrario.

El común denominador de estas hojas suele ser el que presentan desde la base de la espiga, en dirección a la hoja, una parte ancha y plana, equivalente al recazo de la hoja, que a veces lleva dientes laterales (denominados por Quevedo «rejas» en El Buscón Don Pablos).

En la zona de cambio de forma, hacia la hoja, unas veces de forma triangular y otras de verduguillo, se sitúan dos anillos, cerrados o abiertos, cuyo objetivo puede ser romper la punta de la espada adversaria.

El recazo puede tener agujeros o huecos irregulares con el mismo objeto.

Acabado el proceso de labrado de las hojas de espadas o dagas, en el que se ha dado forma a las distintas partes, según su diseño, y superadas las pruebas sucesivamente (sólo en las espadas), se eliminan las ventajas o excesos de medida mediante abrasión por muelas giratorias de madera con polvo de carbón.

Las hojas, finalmente, se pulen o «acicalan» y se marcan o firman.

El PROBLEMA DE LAS MARCAS

El marcado de las espadas es un tema que, históricamente, creemos que no ha sido estudiado en profundidad y en el que se encuentran circunstancias muy contradictorias.

En principio aclararemos que las espadas casi nunca se marcaban o fechaban en las guarniciones, y cuando se hacía en las hojas se efectuaba siempre en el recazo, o en caso de ponerse el nombre del espadero, en el tercio fuerte de la hoja, aprovechando el canal central.

Las marcas en la espiga empiezan a ponerse a partir del siglo xviII. En todas las hojas de los siglos XVI y XVII desmontadas que hemos tenido ocasión de ver personalmente no hémos encontrado marcas ni sellos, y naturalmente las espadas, excepto las primeras limpiezas, cuando hace falta casi una "puesta en luz» inicial, no se suelen desmontar, ya que se trata de una operación delicada, debido al riesgo de agrietamiento del 
botón o de rotura del escudo, por lo que no es posible investigar este extremo sobre piezas montadas.

Desde el siglo xv los reyes españoles legislan creando la figura de los «veedores» o expertos, que entienden en la recepción de lotes de armas y controlan o supervisan, al menos teóricamente, la calidad de las armas. El investigador vasco Sr, Larrañaga ha recopilado abundante documentación, aunque lamentamos que la misma no se refiera al campo de las espadas.

Sin confirmación documental histórica, que no hemos podido encontrar, parece ser que los gremios espaderos, que debieron de tener una gran pujanza, tendrían gran interés en que se certificase mediante una marca, con carácter obligatorio, las piezas acabadas. Y aquí es donde radica el problema. Es cierto que muchas hojas tienen el nombre del espadero o su marca. Concretamente en Toledo es frecuente encontrar la letra T con variantes como especie de garantía de origen. Sin embargo, la duda es ésta: ¿por qué espaderos de la categoría de Sahagún el Viejo, Tomás de Alaya, etc. - hablando, naturalmente, de ejemplares absolutamente auténticos-, no llevan siempre el nombre o su sello, acompañados de las marcas de Toledo donde labraban? ¿Por qué otras veces hojas de alta calidad no tienen marca ni sello alguno y llevan de origen guarniciones de alta calidad? Las respuestas pueden ser muchas.

En el primer caso, es decir, hojas con su nombre y su sello, sin marca de Toledo, cabe pensar que algunos espaderos de renombre tenían «reconocida» su calidad en la época y disponían de la confianza que le otorgaba su categoría.

En cuanto a la segunda pregunta, es dable creer que las hojas sin marca se hacían para eludir controles fiscales, aunque parece ser, por otra parte, que los gremios espaderos tenían privilegio o exención de alcabalas o impuestos.

$\mathrm{Si}$ bien existen relaciones con nombres de espaderos de algunos centros, la denominada Nómina de Francisco Santiago Palomares, escribano mayor de rentas de Toledo de 1760 , nombra a los principales espaderos de los dos siglos anteriores y hace figurar sus marcas. De ella podemos obtener las conclusiones siguientes:

1." Es frecuente que la inicial del nombre o el apellido coincida con la letra de la marca (cuando es una letra).

2." Las letras $T$, que figuran con la marca o sola a veces, no son propias del espadero, sino que son realmente punzones de origen de Toledo. Las diversas posiciones de la letra $O$ acompañando a la $T$ y la forma del escudo que rodea la letra puede que coincida con un período de tiempo o año, igual que en los contrastes de plata en algunos países. 
3." Coincidiendo con las referencias de la Nómina Palomares, hemos encontrado ejemplares en que figuran:

a) Nombre o firma y marca de Toledo.

b) Marca de espadero, y la de Toledo a veces (no siempre, a pesar de ser artífices de Toledo).

c) Nombre y marca de espadero sin punzones de Toledo, como en varios casos de espaderos notables residentes en dicha ciudad.

Es obvio que no ofrecen dudas las falsificaciones con nombres que encierran fonemas erróneos, que demuestran intención de engaño, aunque no sicmpre las transcripciones latinas podían ser tan correctas como deseaba el autor. Hay que tener en cuenta que en la época el campo de las artes aplicadas, como el de la espadería, estaba aislado de otros campos de cultura.

A título de curiosidad, citaremos que Tomás de Ayala, fundador de una dinastía de espaderos notables, no sabía escribir, lo que no le impidió, por otra parte, ejecutar obras excepcionales.

\section{EL ENTORNO HISTÓRICO}

En los comienzos del siglo Xvi se abre un capítulo de inigualable empuje en la historia de España. Carlos I de España, jefe de la Casa de Austria y de Borgoña, inicia y consolida un imperio en continuas guerras, obsesionado por una idea imperial.

Aparece una pléyade de aventureros de temple singular que realizan en América, con fuerzas increíblemente desproporcionadas, las mayores hazañas conocidas en la historia y alcanzan con épicos esfuerzos títulos, honores y riquezas. Las espadas españolas se confrontan desde con las macanas mejicanas (espadas de madera con láminas cortantes de obsidiana) hasta con las de casi íntegramente todos los lugares de la geografía europea en incesantes guerras.

El uso de la espada topera pertenece por derecho a la cumbre de la escala social y aledaños próximos e inferiores: familia real, alta nobleza, caballeros de las Ordenes Militares de Santiago, Calatrava, Alcántara y Montesa, señores de vasallos y patriciado urbano, así como los hidalgos cuya fortuna, a menudo exigua, sólo está compensada por las exenciones de impuestos.

Todo un mundo de antiguas tradiciones, privilegios y férreas etiquetas envuelve el mundo de la espada en el siglo xvi. Símbolo de clase, la ropera representará a veces una obsesión para quien, disfrutando de riquezas, no puede llegar a las castas sociales con las que se identifica la espada. 
Con el tiempo, gentes de guerra con graduación, aventureros de éxito, hombres de letras y personajes adinerados van accediendo progresivamente al uso de la espada y generalizando derechos antes muy restringidos.

Sobre todo en las ciudades residencia de la Corte en distintas épocas, Toledo, Madrid y Valladolid, el duelo y las pendencias con espada se prodigan. No basta su condena en el Concilio de Trento $(3$ de diciembre de 1563, sesión 25) con la pena de excomunión, ni las distintas disposiciones oficiales para reprimir la vieja costumbre de defender el honor con la espada en la mano.

Conscientes de ello, los decretos reales van refiriéndose cada vez más a tratar, por lo menos, de que los «encuentros» sean lo menos alevosos posible. Además de la disposición de Felipe II antes citada referente a la longitud de las espadas, Felipe III, en 1615, prohíbe «llevar cuchillos en las dichas espadas», y Felipe IV, el uso de «vainas abiertas, sujetas con agujas o con muelles en el brocal», y que tenían por objeto desenvainar más fácilmente de lado o clavar la punta sin desenfundar, al llevar disimulado el extremo de la espada sobresaliente con papel plateado o dorado, a modo de contera.

En el siglo xvi se inicia una industria de armas que servirá de soporte a las necesidades crecientes de guerra y fabricará también armas de ornato y defensa. Sin embargo, a pesar de la inicial pujanza económico-social de la primera mitad del siglo xvI, no se estructura una auténtica sociedad artesanal e industrial.

En la situación inciden factores muy complejos. El Renacimiento ideológico y renacentista es reprimido por la Contrarreforma y la mano férrea de la Iglesia, que a la par que controla cualquier desviación religiosa con la Inquisición, ocupa un lugar increíble en la economía. En el siglo Xvi el clero, con un 2 por 100 de la población, dispone del 60 por 100 de las rentas del país.

El trabajo manual, que en los países protestantes es considerado como una proyección de realización personal, se interpreta en España casi como un castigo divino. Todo ello no facilita ni la inversión ni el desarrollo industrial.

Otro factor es el endeudamiento de guerra del Estado con los grandes banqueros internacionales: Welser, Fugger, Médici, etc., que se les compensa en parte con licencias de explotaciones mineras y concesiones de exclusiva de compras de materias primas, que se exportan, lo que impide el desarrollo de las actividades transformadoras. Incluso el mundo comercial de las transacciones internacionales ha perdido a eminentes judíos españoles expertos en el tema durante el siglo xv. 
Además, la fuente de ingresos que constituyen las remesas de oro de América no bastan en el siglo xviı para cubrir los gastos de las guerras de Flandes (concretamente se estima el gasto de guerra en el doble del valor de las remesas de metales preciosos). El oro simplemente se trasvasa a Europa, donde se emplea para crear una sociedad industrial incipiente.

Todo este marco económico forma los pies de barro de un gigantesco imperio, conseguido con singularidades individuales y con actos heroicos de pequeños grupos, pero que tiene una inestabilidad sociológica profunda al carecer de un auténtico soporte de progreso.

En medio de estas dificultades, los artesanos, en nuestro caso los espaderos, luchan por defender su grupo social con las asociaciones gremiales, que tienen por objetivos fundamentales velar por sus intereses, fijar normas de ascensos profesionales, acordar salarios, ayudar a enfermos y ancianos, etc.

Este esfuerzo es una continua lucha de clase para conseguir una consideración de justicia que muchas veces tropieza con la influencia religiosa. Por ejemplo, se llega a obligar a los maestros a tener que demostrar «limpieza de sangre», es decir, no tener antecedentes próximos judíos ni moros en su linaje.

De la auténtica discriminación de la clase del trabajo da idea el que los pintores lucharan para que no se les incluyera en el pago de alcabalas con los artesanos y no se les prohibiese el uso de vestidos de seda. Incluso Velázquez tuvo problemas para vestir el hábito de caballero.

En Toledo, que es el centro geográfico y comunicado radialmente con todo el país, se desarrolla una industria artesanal espadera cuyos gremios trabajan en la calle de las Armas y en el callejón de la Lamparilla, hoy desaparecidos, y que alcanzan por indiscutible mérito la más alta fama internacional.

Para dar idea del aprecio de la calidad de las fabricaciones de Toledo sirve de indicativo una Cédula Real, impresa por Julián de Paredes en 1680 , donde se fijan los precios máximos de hoja y guarniciones.

Se dice en ella:

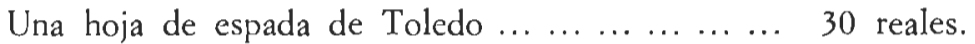

Una hoja de espada de Alemania ... ... .......... 18 reales.

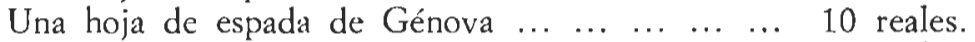

Una hoja de espada de Tolosa de. Francia $\ldots . . . .11$ reales.

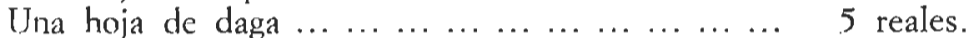

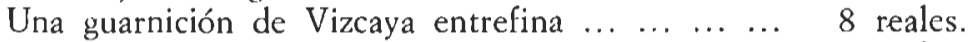

$\begin{array}{lllllll}\text { Una guarnición entreordinaria } & . . & \ldots & \ldots & \ldots & \ldots & \ldots\end{array} 6$ reales. 
Una guarnición fina de dos manos ............ 10 reales.

Una guarnición labrada, lisa, llana y esmerilada ... 36 reales.

Una guarnición de daga $\ldots \ldots \ldots \ldots \ldots$ la mitad que la de una espada de su misma calidad *.

A mediados del siglo xvr se inicia lentamente la decadencia económica, que se va agudizando hasta alcanzar límites de desastre en el siglo xvir. Las ciudades del interior se despueblan por causa de las emigraciones y las epidemias. Toledo pasa de 55.000 habitantes en 1550 a 20.000 en 1650.

Con el progresivo declive económico y político se exacerban en el siglo xvi las frustraciones espirituales de las clases privilegiadas y no es difícil que surjan duelos, lances y peleas por los motivos más nimios.

El uso de la espada se hace insustituible como elemento de defensa en las ciudades, donde el desempleo y la miseria han hecho estragos en las clases bajas, que a menudo alternan a probar fortuna entre las levas de soldados y el bandidaje.

Toda esta picaresca abigarrada, consecuencia del empobrecimiento económico producido y la escasez de medios económicos del Estado, que deja en manos de las Ordenes religiosas el paliativo de remediar por la caridad el hambre y la miseria de los desheredados, origina un clima de inseguridad en las ciudades.

Las armas de fuego aún no encajan con el sentido religioso y de honor, lo que hace que se considere el uso de la pistola como propia de gente de ventaja o de condición poco noble. No puede imaginarse un caballero llevando por las calles de la corte una pistola. Sólo hombres de guerra y en excepcionales ocasiones, como viajes, podrán llevar estos instrumentos de muerte.

La espada, en cambio, parece que se estima como algo más que un elemento de defensa y ornato: es una prolongación de la idiosincrasia de lucha y encarna el honor individual entre el eterno contraste de la vida y la muerte que subyace en el alma española.

Los grandes escritores del Siglo de Oro reflejan extraordinariamente la sociedad de la época en las comedias de capa y espada. Citas literarias de varias épocas ensalzan la espada de Toledo.

Cervantes dice en el Quijote: «Con una sola espada y no de las 'del perrillo' cortadora» (se refiere a la marca de Julián del Rey).

* Nota: Como referencia, un capitán de tercios ganaba 40 libras al mes y un oficial artesano del orden de 12 reales día. Un real de a 8 podría suponer hoy unas 2.500 pesetas. 
Lope de Vega, en Las flores de Don Juan, pone en boca del espadero y Don Alonso el siguiente diálogo:

\author{
Espadero: Vive Dios que es un diamante. \\ Don Alonso: Aun el diamante es común, \\ que espada de Sahagún \\ no ha de tener semejante.
}

No es infrecuente que la gente de letras maneje la espada con la habilidad de la pluma. Quevedo, que además de genial escritor es también un hábil espadachín, protagoniza en 1608 un desafío, por discusiones técnicas de esgrima con el maestro Luis Pacheco de Narváez, del que sale vencedor.

La moda de esgrimir en el siglo xvil está cada vez más extendida, hasta el punto de constituil un público espectáculo los tiradores de las distintas escuelas de Madrid, Sevilla, Córdoba, etc., que se desafían y luchan con espadas de punta roma en las plazas de las villas entre aglomeraciones espontáneas de la gente, a la que a veces el maestro, accionando el montante en círculo, tiene que mantener separada.

Dspués de producirse los ejemplares más bellos en la mitad del siglo xvII, la industria armera decae y se van perdiendo las viejas técnicas de los grandes maestros. Dionisio Corrientes, uno de los últimos venerables artesanos que labran al viejo estilo, muere en 1733.

La descomposición del Imperio es un hecho a fines del siglo Xvir. Carlos II, el último monarca de la Casa de Austria, todavía nominalmente señor del mayor imperio conocido y cuyo proyecto de reparto gestan ya las monarquías europeas, tiene a veces tan graves problemas económicos que frecuenta visitas a sus nobles para poder pagar a la servidumbre con la venta de los regalos que éstos le hacen.

Con el siglo xvir, y a la muerte de Carlos II, se cierra el capítulo imperial de los Austrias en España y también un mundo de grandezas y miserias arquetípico, consustancial con la espada ropera.

La espada española muere también y se producirán algunos hermosos ejemplares antes de ceder el paso definitivo al espadín cortesano, cuyo uso nace con la Casa de Borbón y el Siglo de las Luces. 


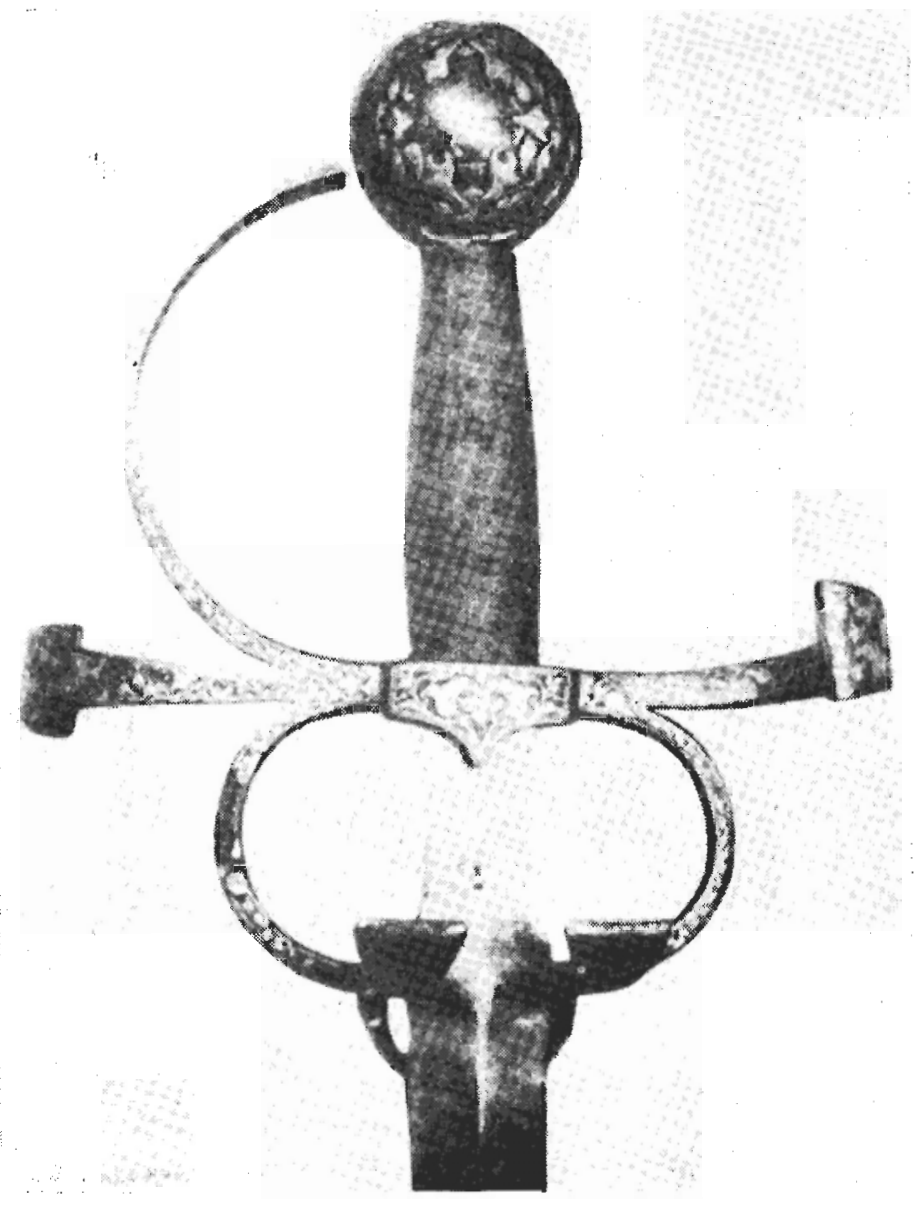

Fotografía N." 1. Espada española, con hoja de cuatro mesas, recazo grueso, trabajo de ataujía de oro, pomo circular de dos fachadas, gavilanes de forma sigmoidea y contraguarda de anillo. Lleva grabadas las letras IHS (JESUS). Obra de Mateo DuARte, espadero valenciano que vivía en Valencia en 1543. Esta espada se cree pertenecía a Fran. cisco Pizarro, conquistador del Perú, muerto en 1541. Catalogada G. 35. Armería Real de Madrid. Primer tercio siglo xvI. 


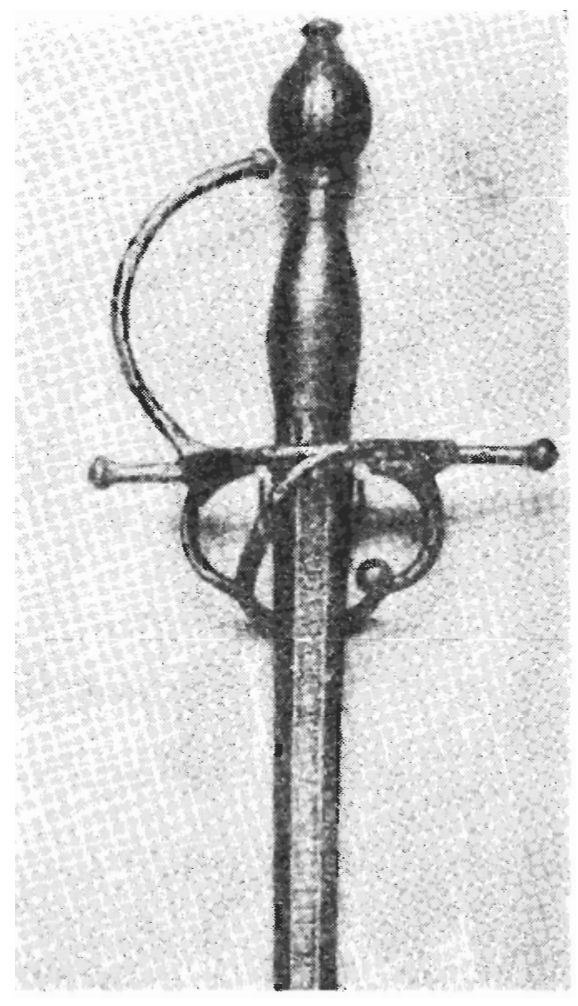

Fotografía N." 2. Espada española, por Manuel Gonales. Segun. do tercio del siglo xvi, probablemente hacia 1540.

Fotografí N. ${ }^{\circ} 3$. Espada española, por López Aguado, de l'oledo. Segundo tercio del siglo XVI.

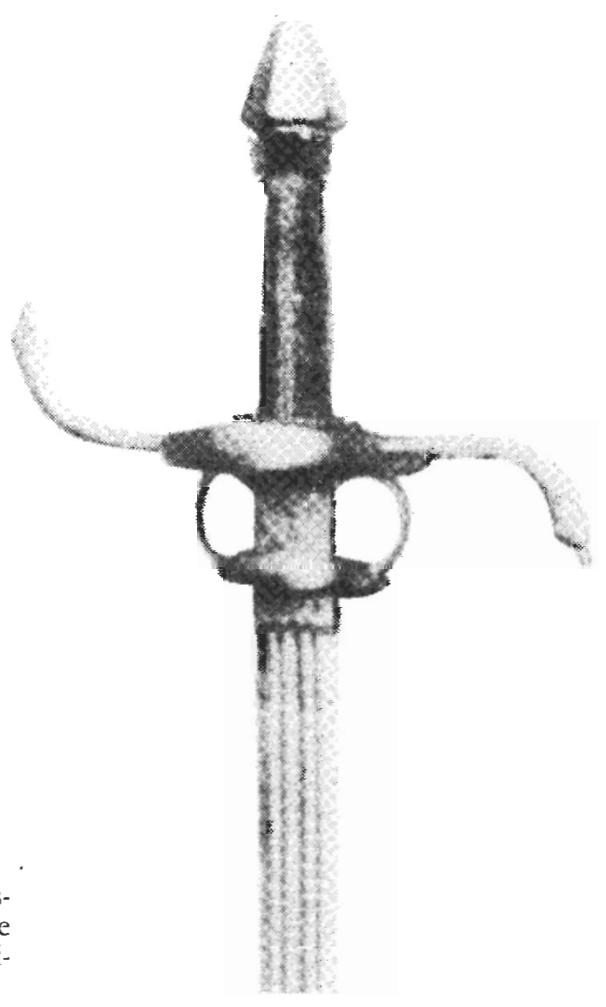


Fotograrí N." 4. Corresponde a una espada española, por el espadero valenciano EsTEBAN. Tercer tercio del siglo xvi.
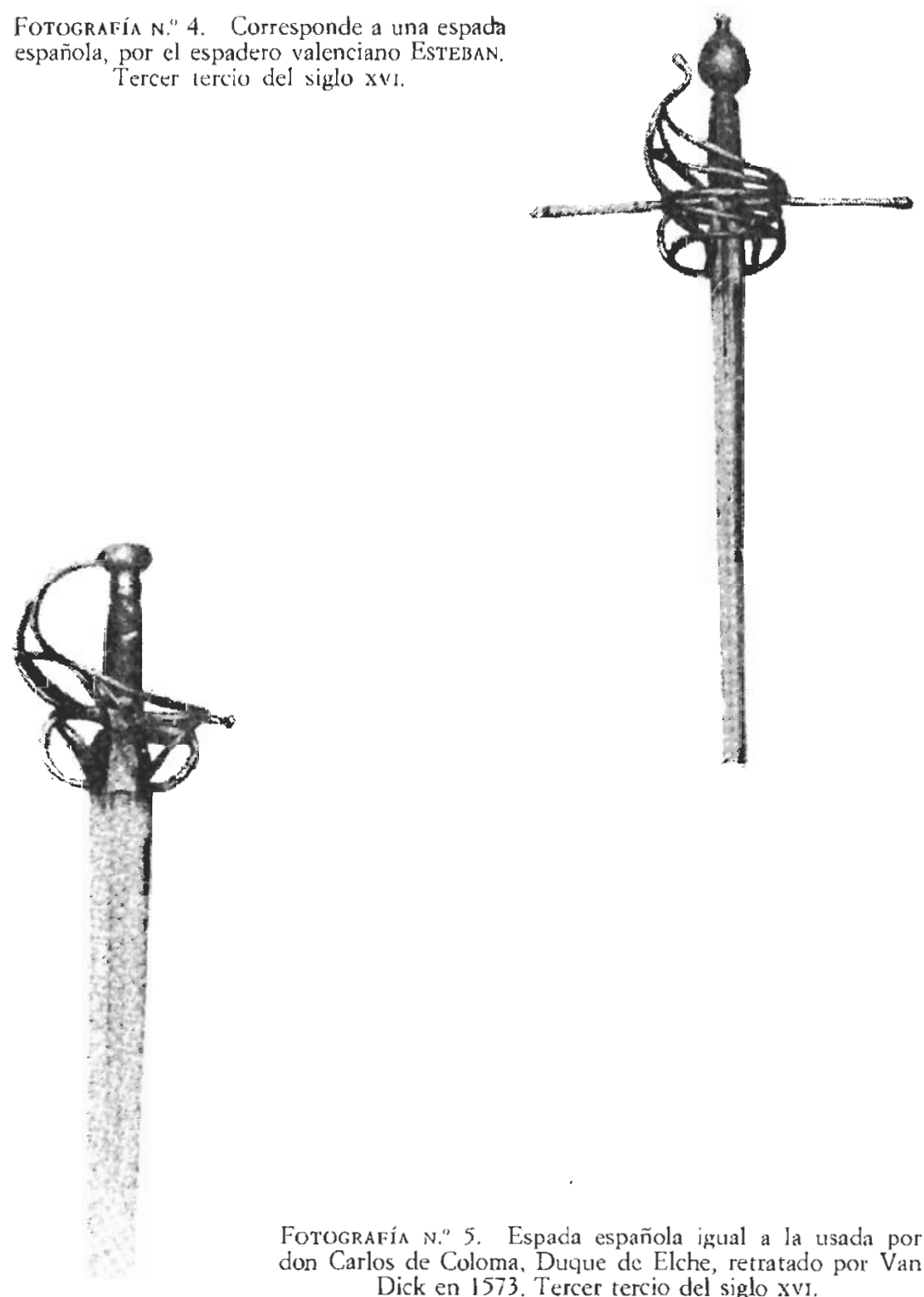

Fotografía i." 5. Espada española igual a la usada por don Carlos de Coloma, Duque de Elche, retratado por Van Dick en 1573. Tercer tercio del siglo xvi. 


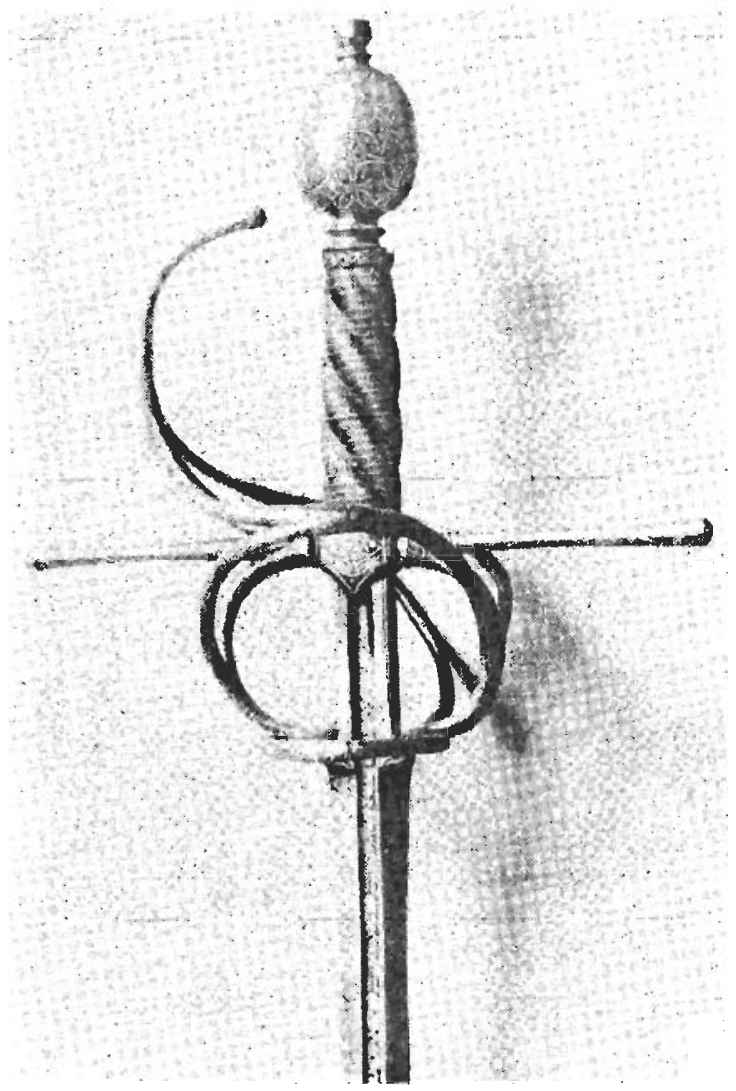

Fotografía No ${ }^{\circ}$ 6. Espada con guarnición italiana o de influencia italiana. Incrustaciones de plata. La hoja indica «MONTE EN TOLEDO, ESPADERO DEL REY» (se conocen de él obras fechadas en 1610 y 1630). Primer tercio del siglo xvir. 


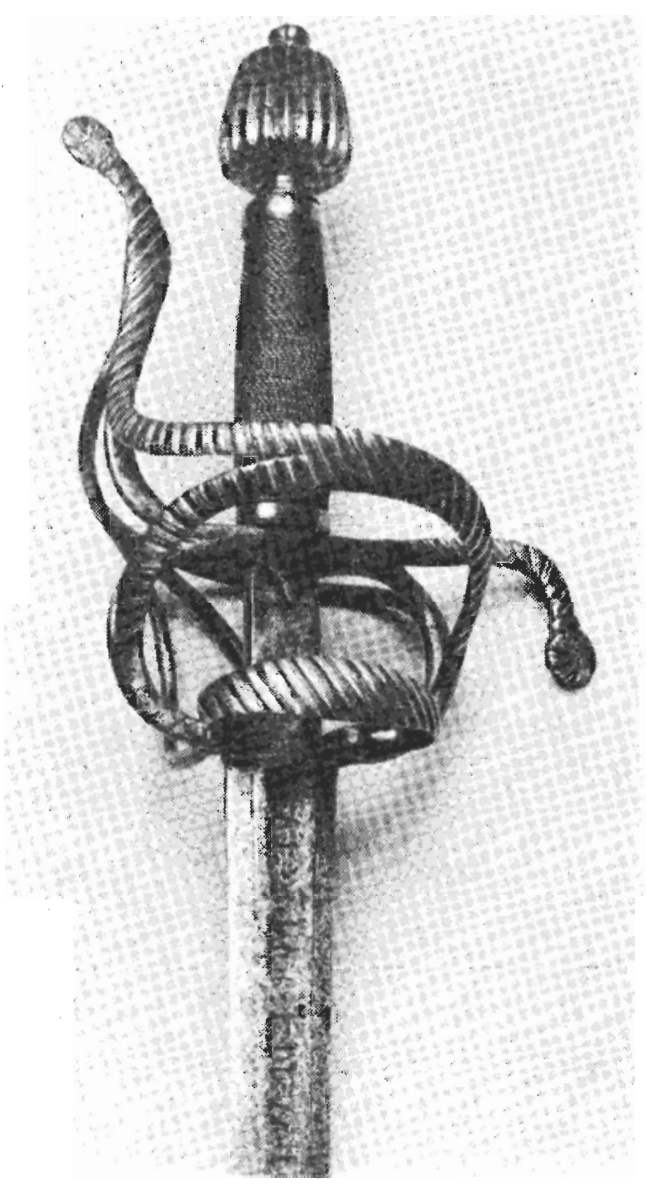

Fotografía n." 7. Espada con guarnición alemana o española al gusto alemán; incrustaciones de aleación de plata. Hoja alemana con inscripción: «IN ALEMANIA ME FECIT». Marcas en la hoja no interpretables. Finales del siglo xvi o principios del xvil. Colección particular. 


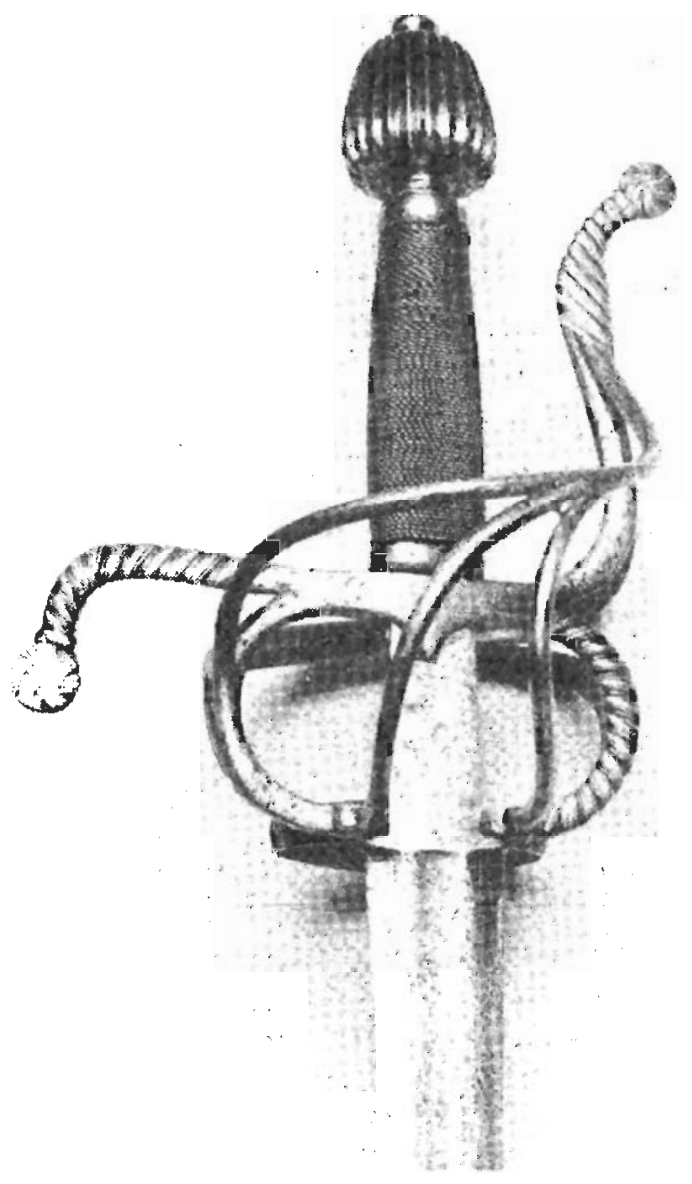

Fotografí n ${ }^{\circ} 8$. Contraguarda de la espada anterior. 


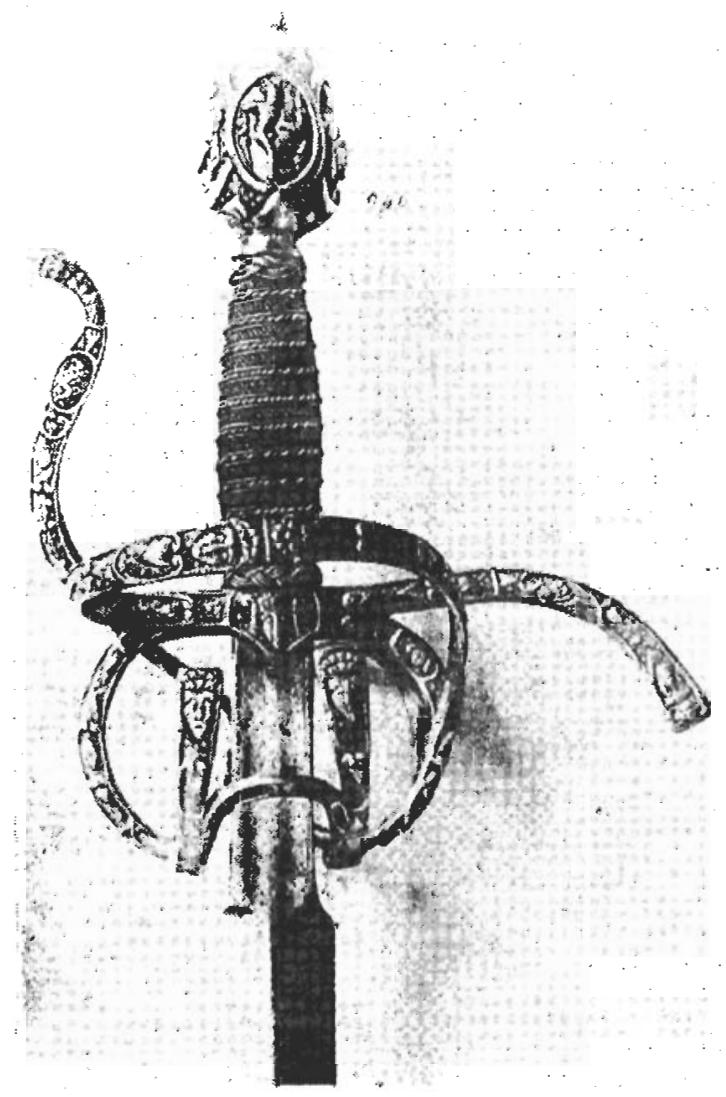

Fotogratía N. ${ }^{\circ}$ 9. Espada con guarnición italiana o toledana de estilo italiano. Hoja española de estoque. Primer tercio del siglo xvir. 


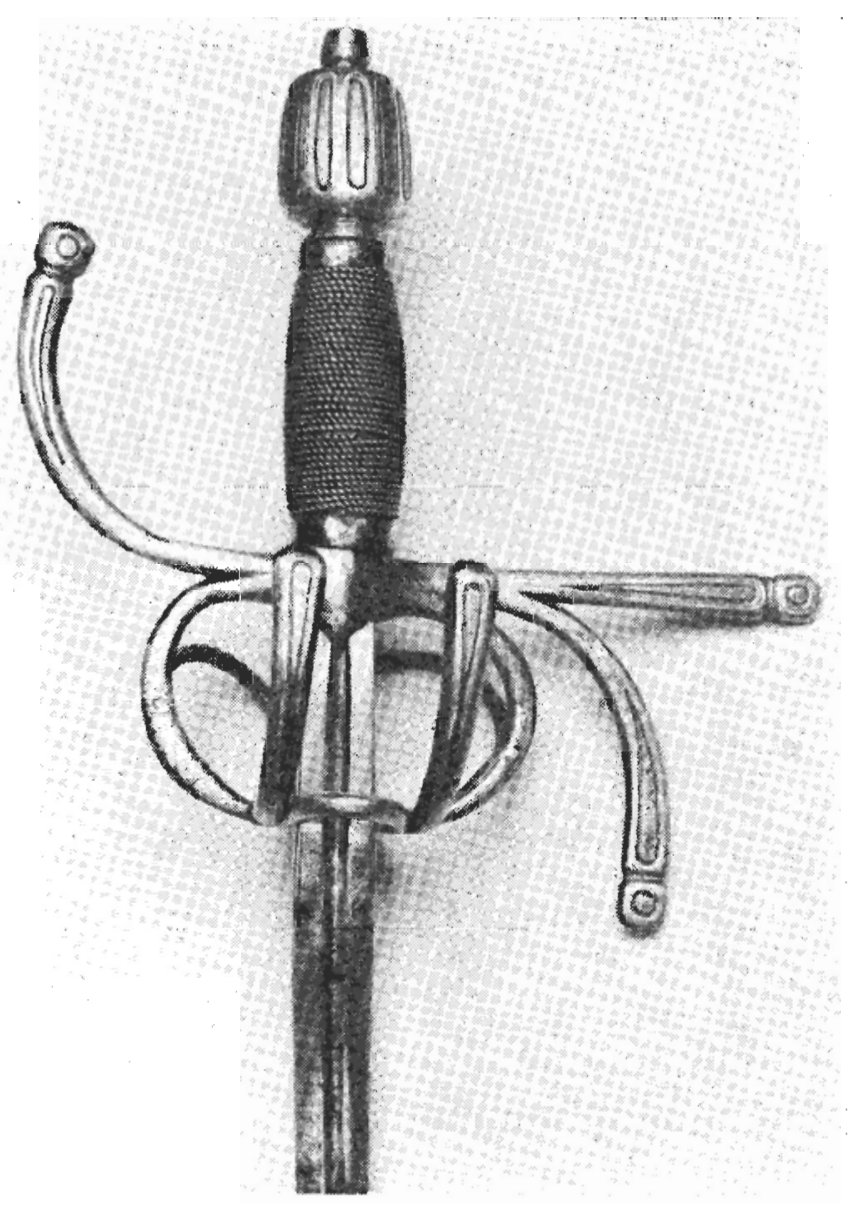

Fotografía N." 10. Espada española con guarnición incrustada en aleación de plata. Hoja española, probablemente del espadero ANTONIO RODRíguez (véase detalle de la fotografía de la leyenda de la hoja). Principios del siglo xvir. Colección particular. 


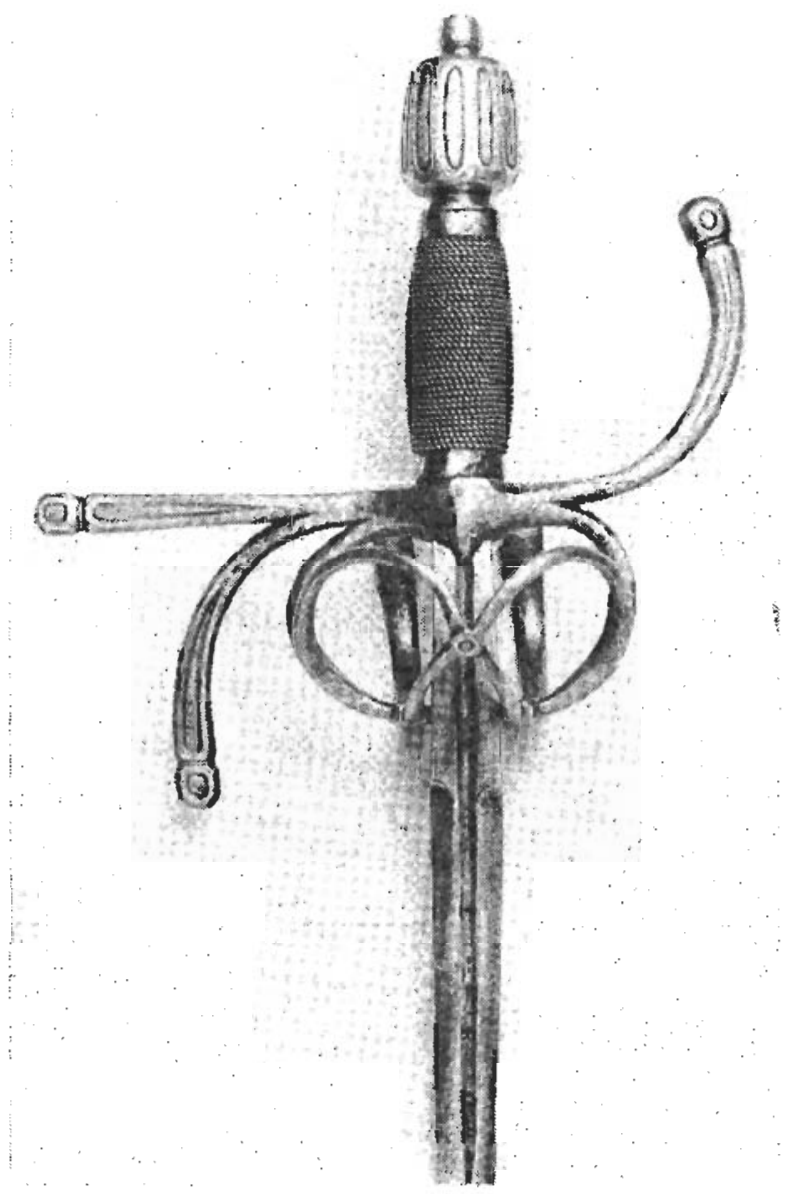

Fotografía N." Il. Contraguarda de la espada anterior. 


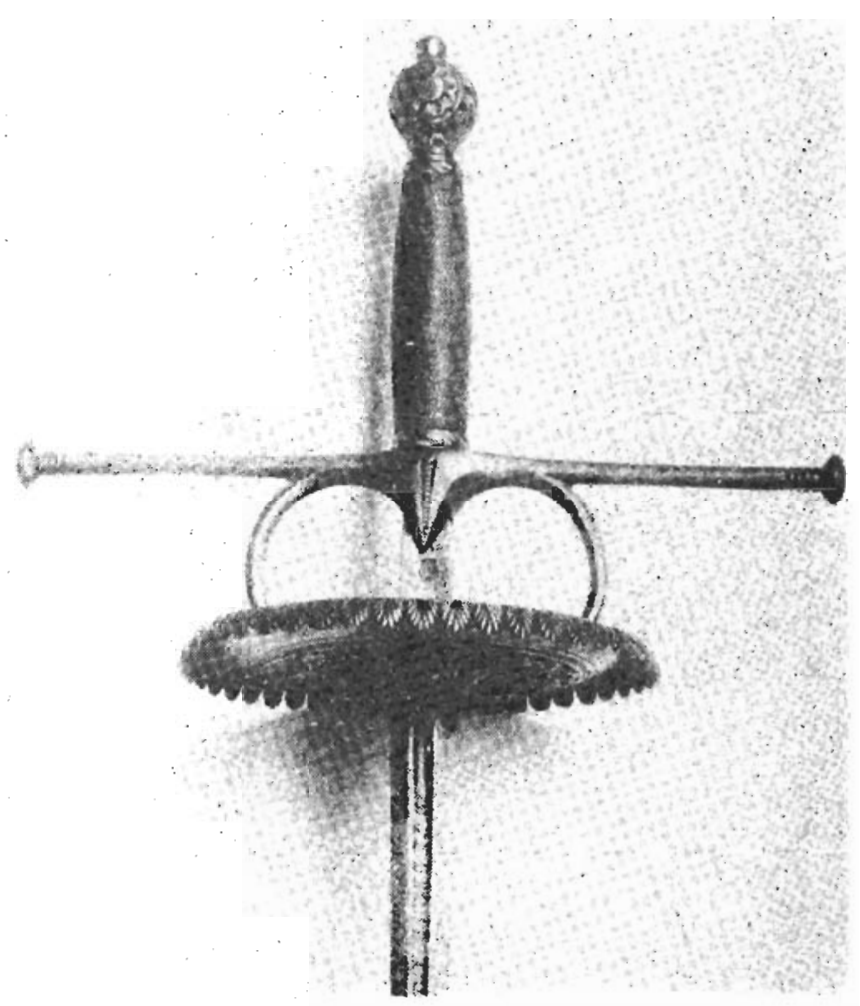

Fotografía N." 12, Espada española de verduguillo, de guarnición de plato, con rompepuntas. Hoja anterior de PEDRO DE TORO en 1580. Primer tercio del siglo XvII. 


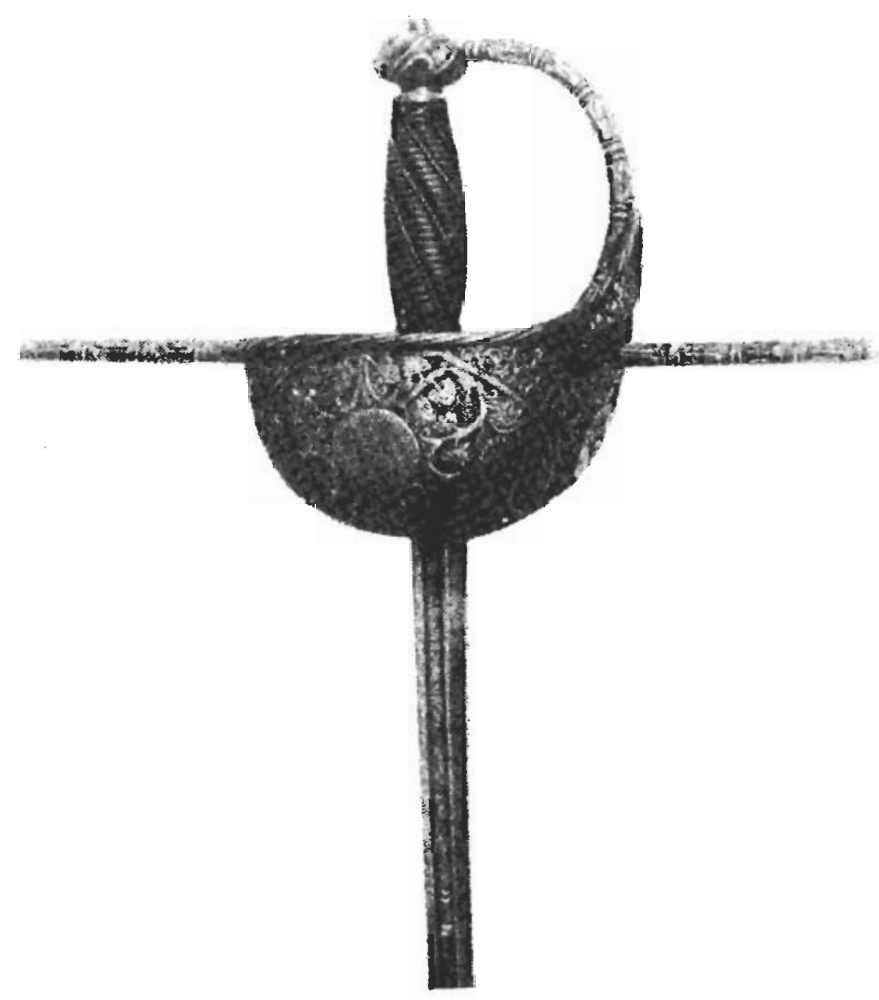

Fotografía N.: 13. Espada española de taza con un lado acestado. Obra de Francisco Ruiz en Toledo en 1617. 


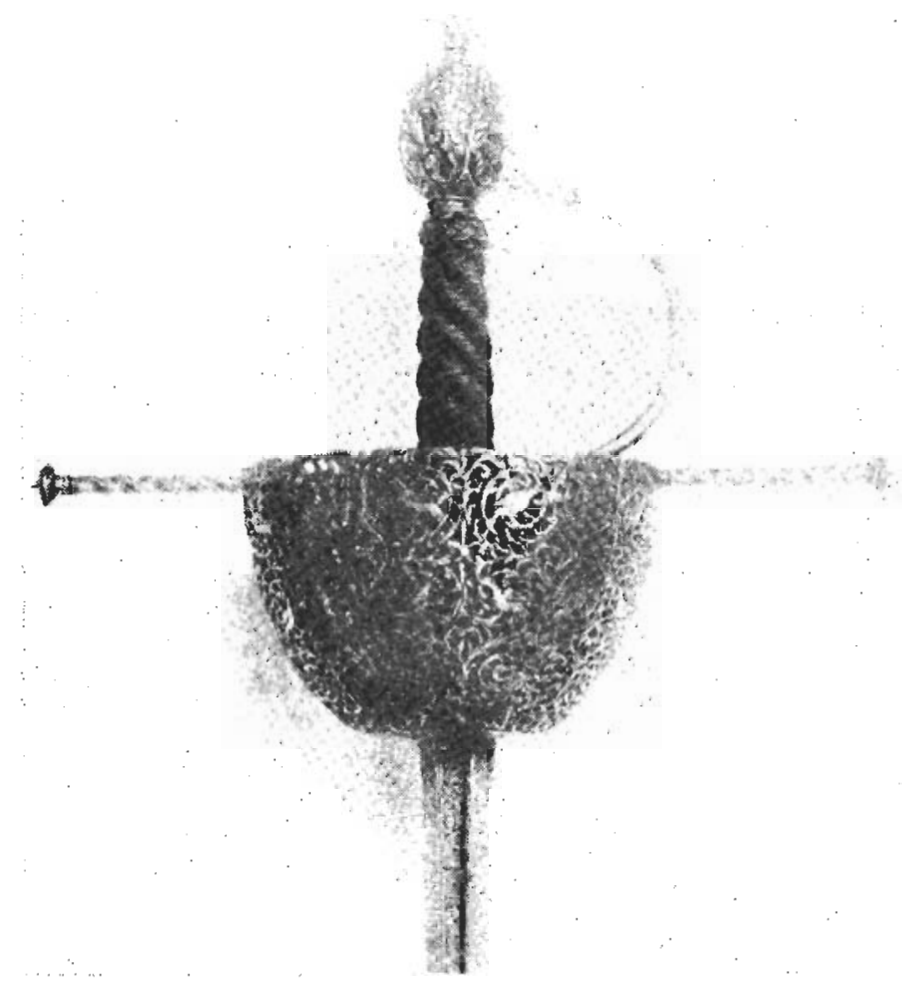

Fotografía N. ${ }^{\circ}$ 14. Espada española de taza o cazoleta «de huevo», calada, hoja con la inscripción «PETRUS, EN TOLETA». Segunda mitad del siglo xVIr. 


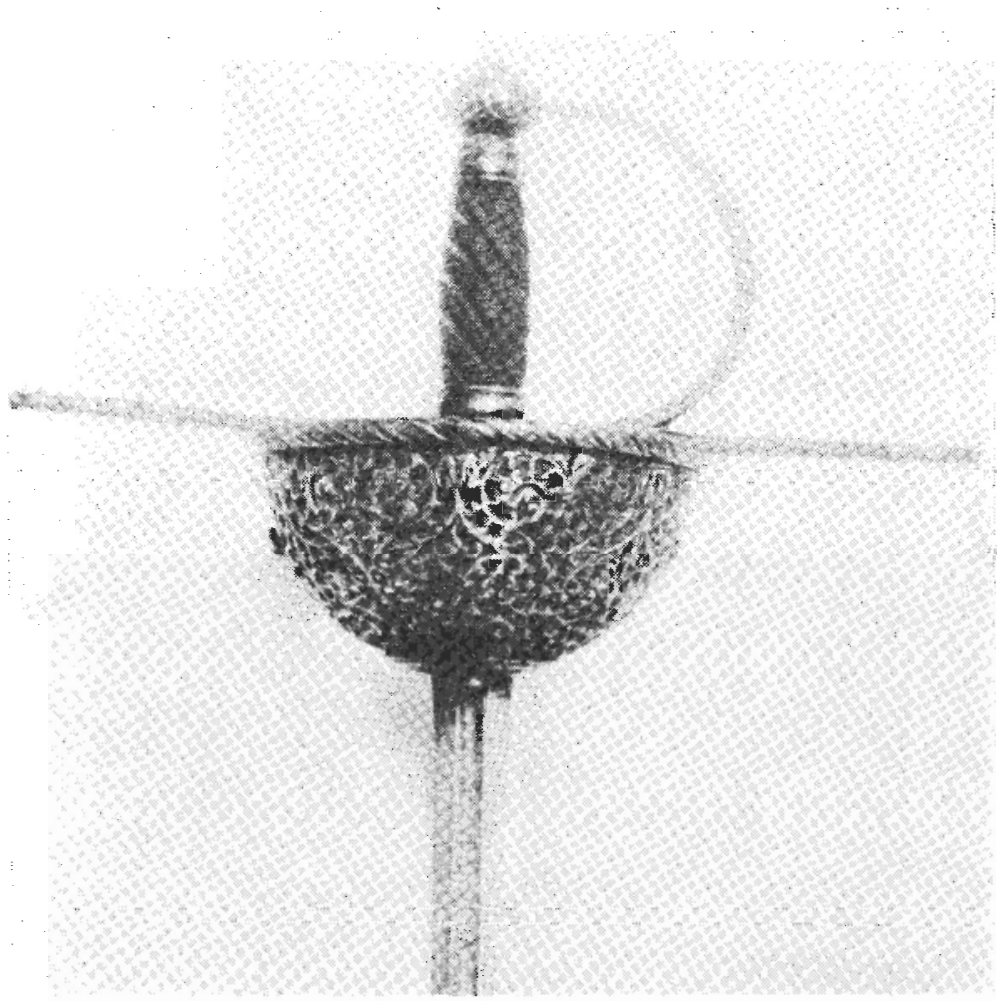

Fotografía N. ${ }^{\circ}$ 15. Espada española de taza calada. La hoja lleva la inscripción «TOMAS DE AYALA», 1625. Aunque los Ayala constituyeron una larga dinastía no bien conocida, el primer Tomás de Ayala fue contemporáneo de Alonso de Sahagún el Viejo, a quien compró una casa en Toledo en 1572, y murió en 1583. Mediados del siglo xvII. 


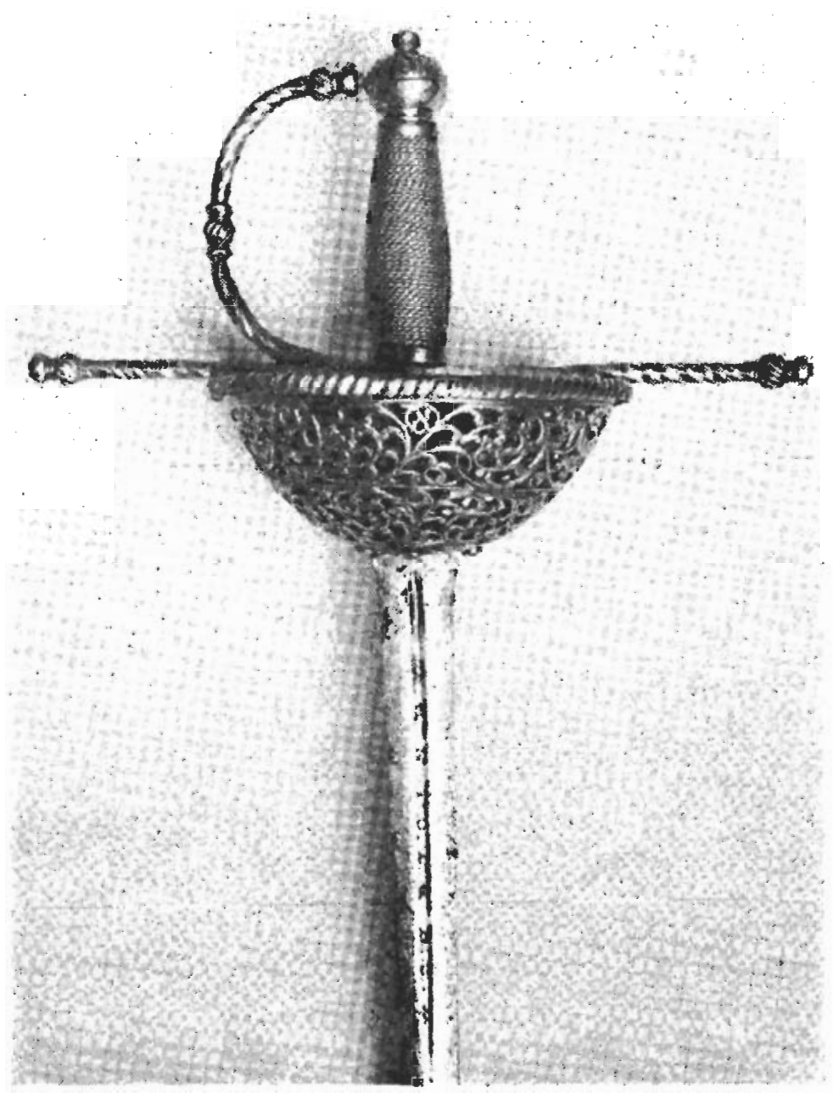

Fotografía N. ${ }^{0}$ 16. Espada española de taza, calada, hoja con Ia inscripción «EN TOLEDO». Segundo tercio del siglo xvir. Colección particular. 


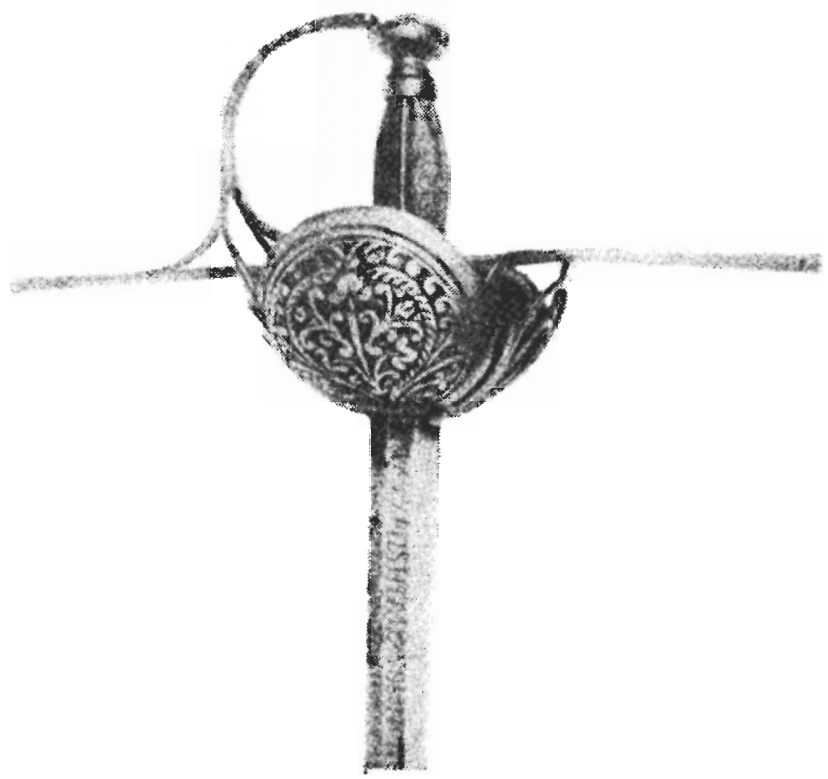

Fotografía N. ${ }^{\circ}$ 17. Espada española de conchas, de hoja ancha con la inscripción «MI SINAL ES EL NOMBRE DE IESUS, ESPADERO EN ALEMANIA». Mediados del siglo XVII. 


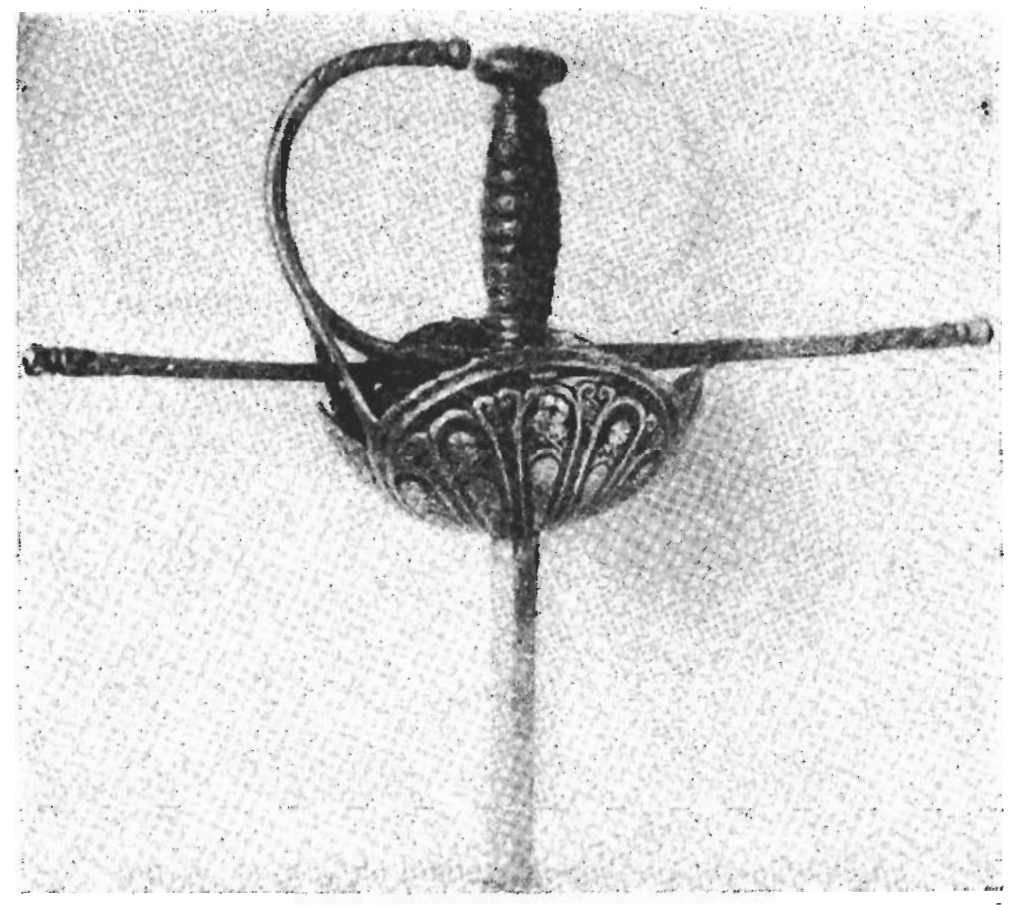

Fotografía N..$^{\circ}$ 18. Espada española de conchas, de hoja de verduguillo. Segunda mitad del siglo xvir. 


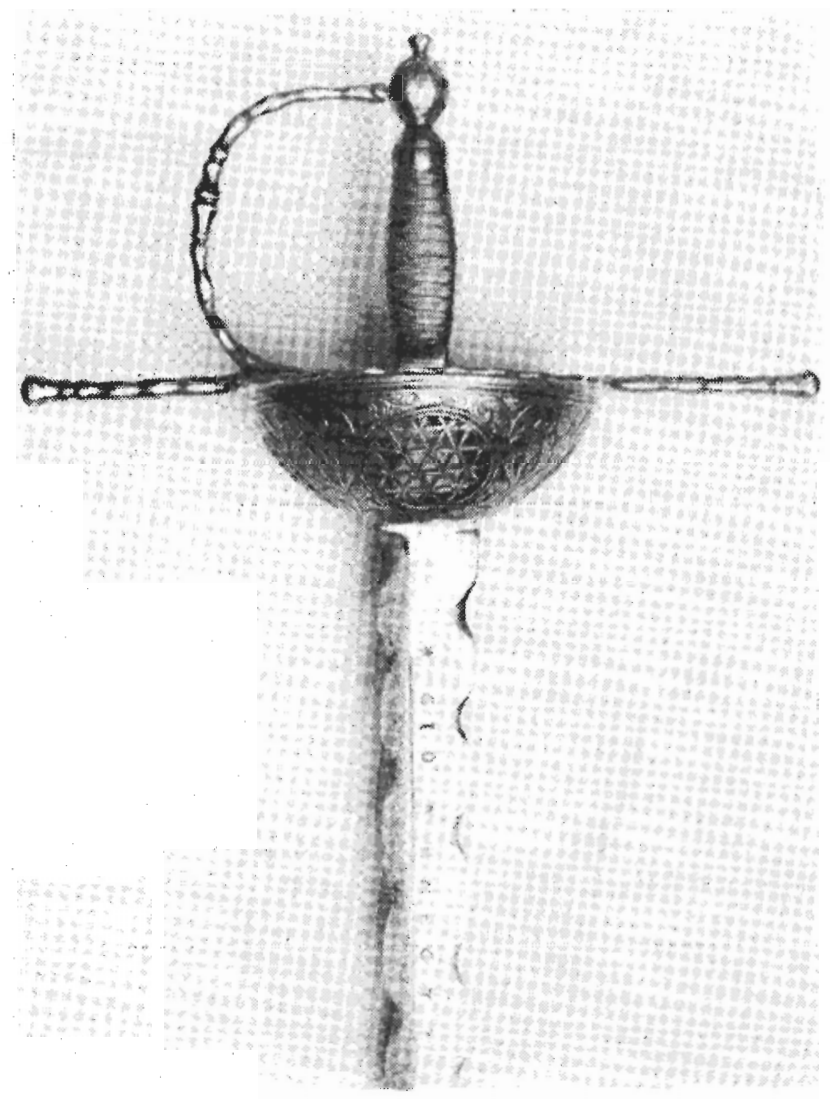

Fotografía N. ${ }^{\circ}$ 19. Espada con guarnición española de taza, de Toledo, con cuatro ventanas circulares caladas. Dos opuestas con dibujo de influencia mudéjar. Hoja flamígera de Solingen firmada por Gio KNEGT, de dinastía notable de espaderos alemanes. Colección particular. Tercer tercio del siglo xvir. 


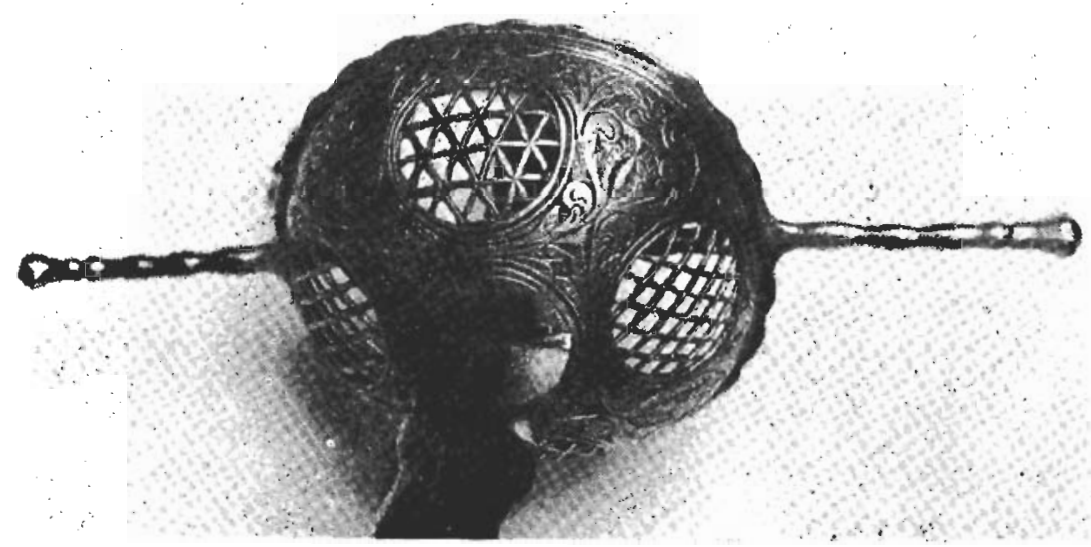

Fotograyía n. 20. Detalle de la guarnición anterior.

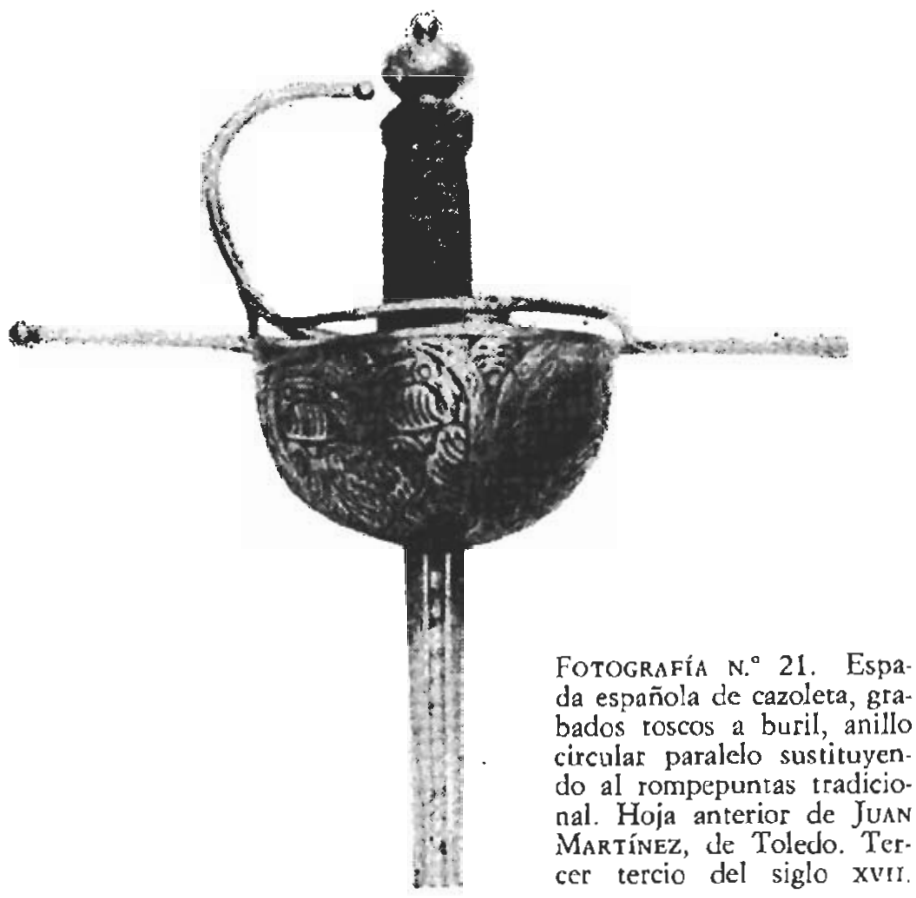




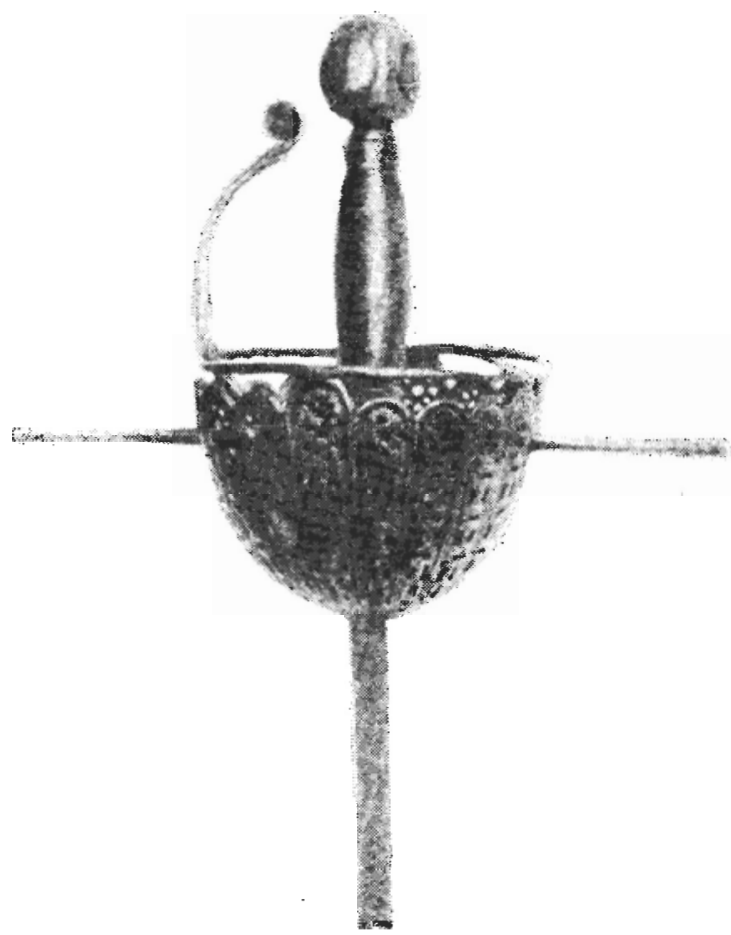

Fotografía N. ${ }^{\circ} 22$. Espada española de cazoleta de huevo, con anillo circular superior en vez de rompepuntas. Hoja de verduguillo de sección rectangular de Dionisio Corrientes. Finales del siglo Xvil. 


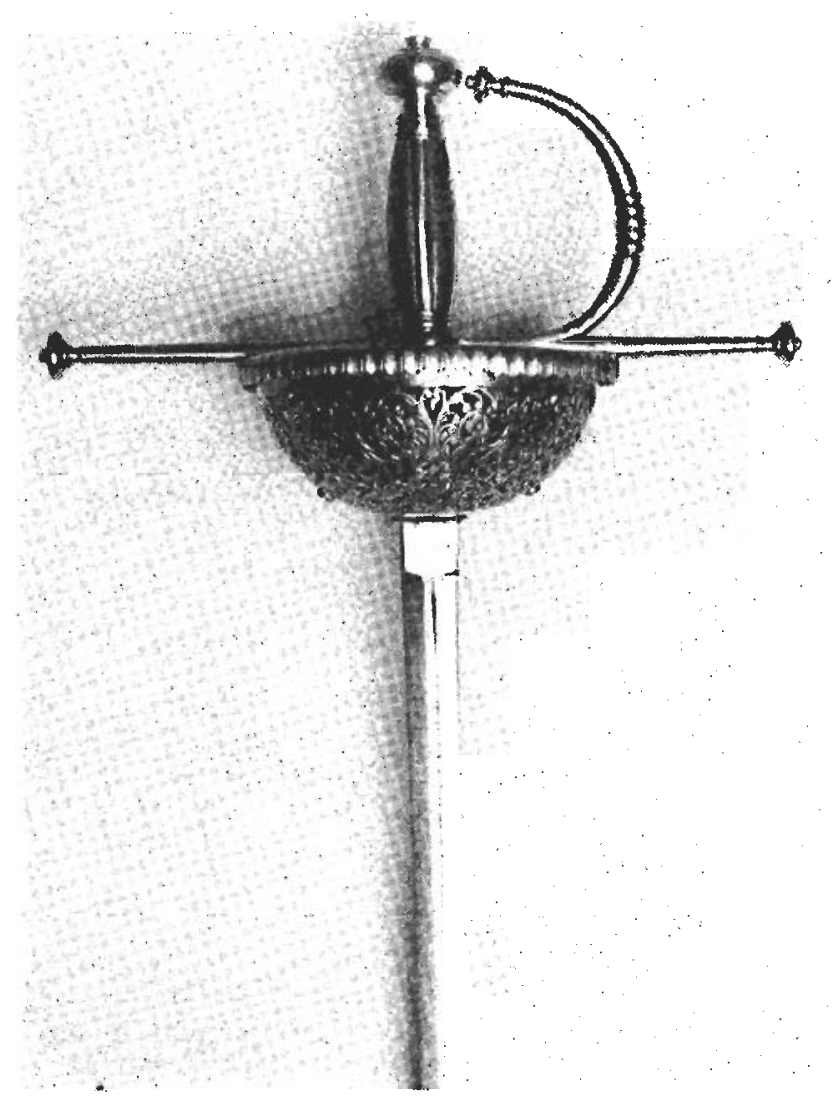

Fotografía N.a 23. Versión posterior de espada española de taza calada, Toledo. Probablemente hecha como ejemplar de presentación o como muestra de continuidad artesana. Siglo xix. Colección particular. 
Fotografía N. ${ }^{0} 24$. Daga de mano i\%quierda española con guarnición de concha y pomo pavonados, fechada en 1580 .

Marca de Toledo. Colección particular.

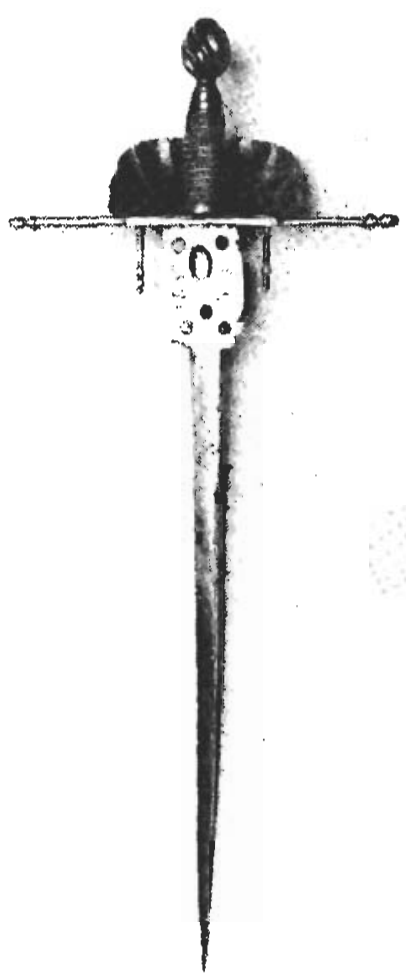

Fotografía N. ${ }^{\circ}$ 25. Dorso de la daga anterior.

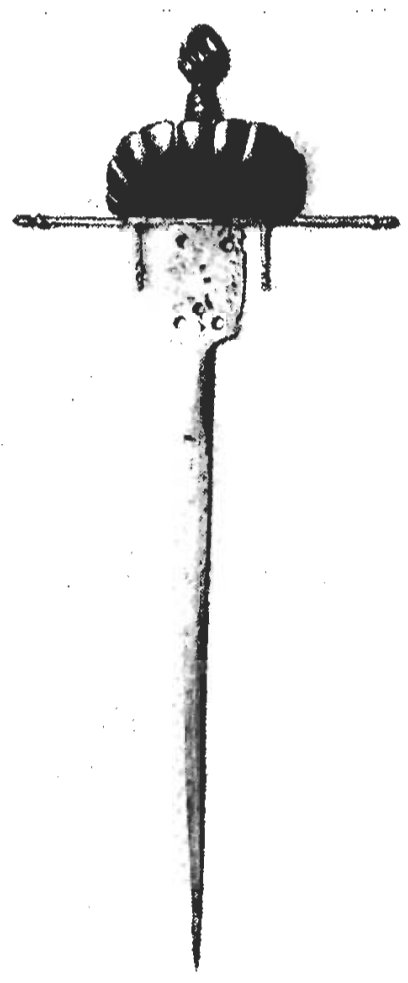




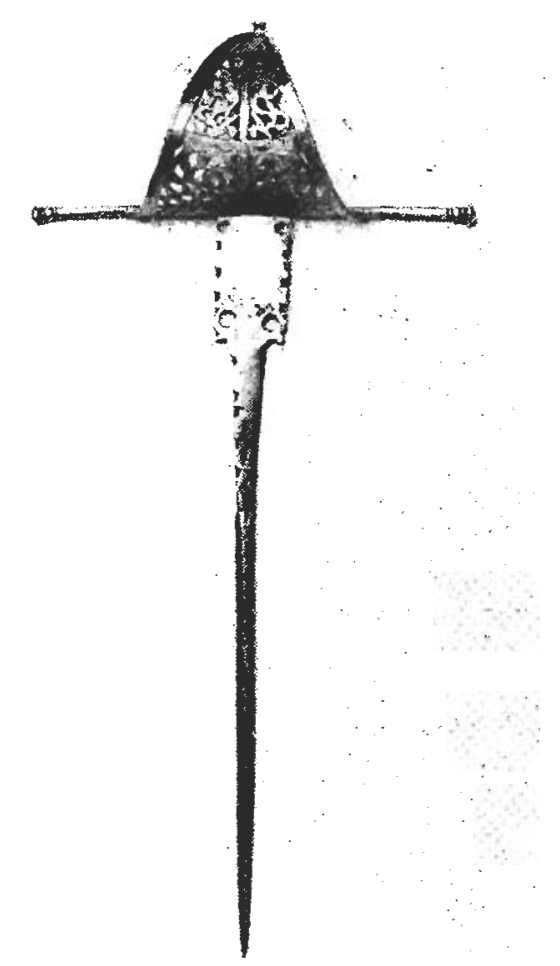

FotografíA N. ${ }^{\circ}$ 26. Daga española de vela triangular calada con rompepuntas, marca de Toledo. Siglo xviI. Colección particular.

Fotografía No, 27. Dorso de la daga

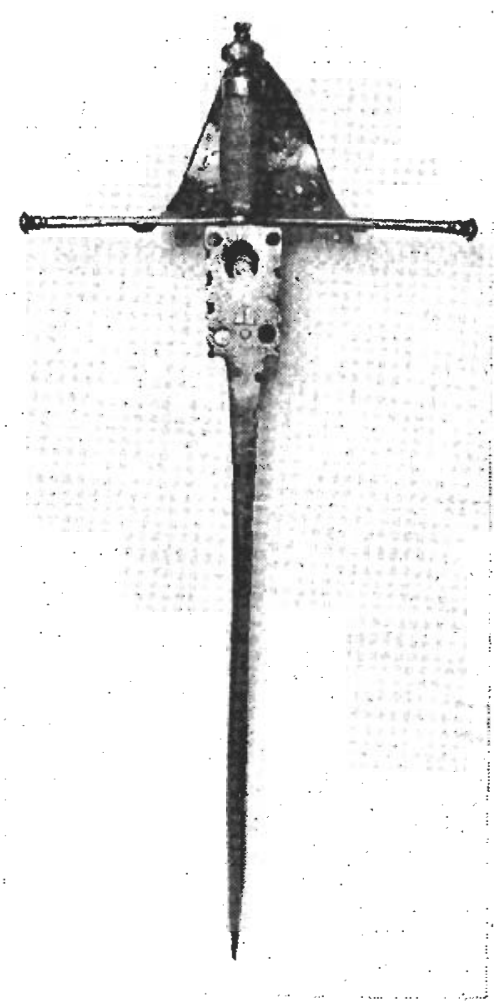

192 


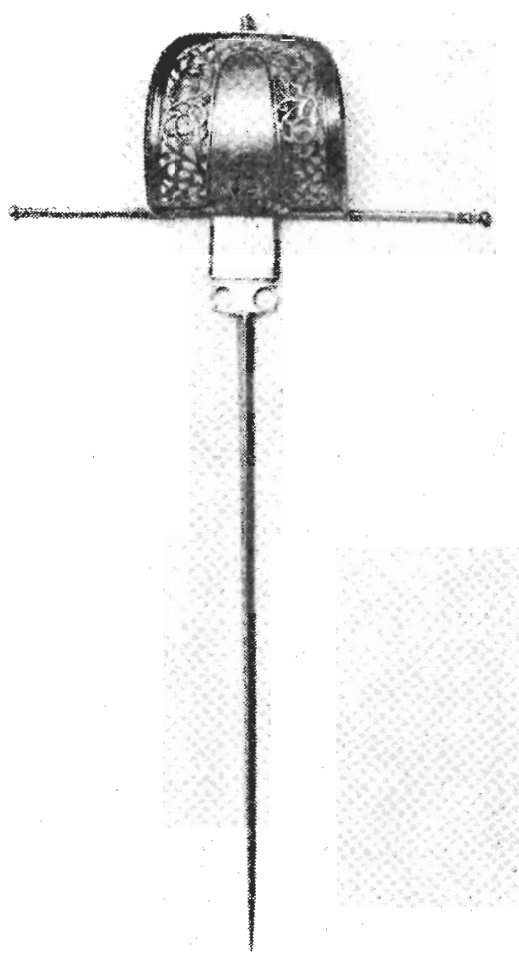

Fótografí n.$^{\circ}$ 28. Daga de mano izquierda, española, con calados y adornos superpuestos en la zona próxima al recazo. Rompepuntas. Hoja de verduguillo. Siglo xvir. Colección particular. 


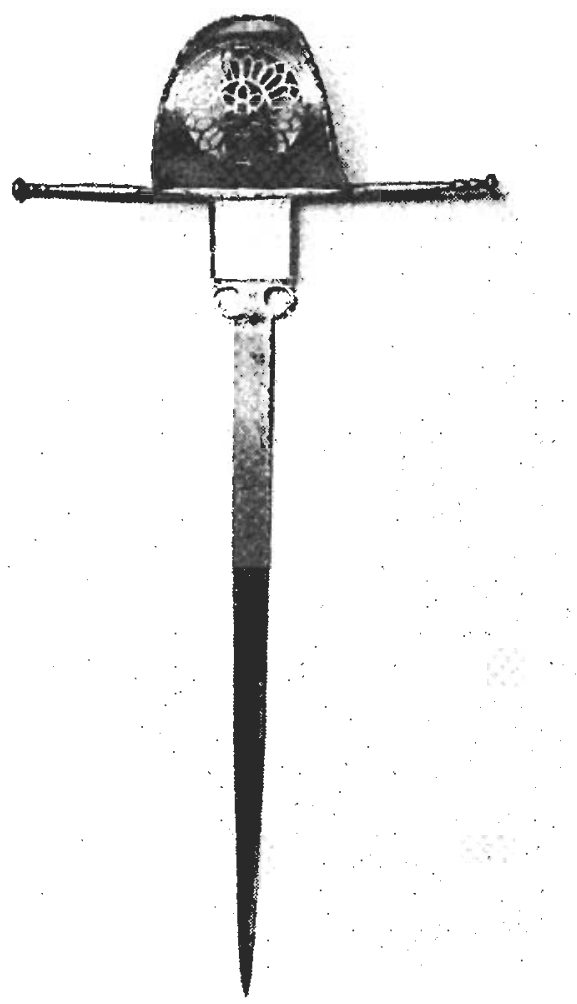

Fotografía N. ${ }^{0} 29$. Daga de mano izquierda, española, con calado central de rosetón estilo gótico y rompepuntas a juego con los dibujos del lomo de la hoja. En el centro del rosetón lleva calada la estrella de David. Marca de Drego López, hoja grabada a buril con dibujos de adorno y la figura de un toro. (véase fotografía de detalle). Colección particular. Hacia 1650. 
Fotografía n. 30 . Daga de mano izquierda, española, con rompepuntas, calados y gavilanes torcidos en espiral de sección creciente hacia las puntas. Colección particular. Mediados del siglo Xvir.

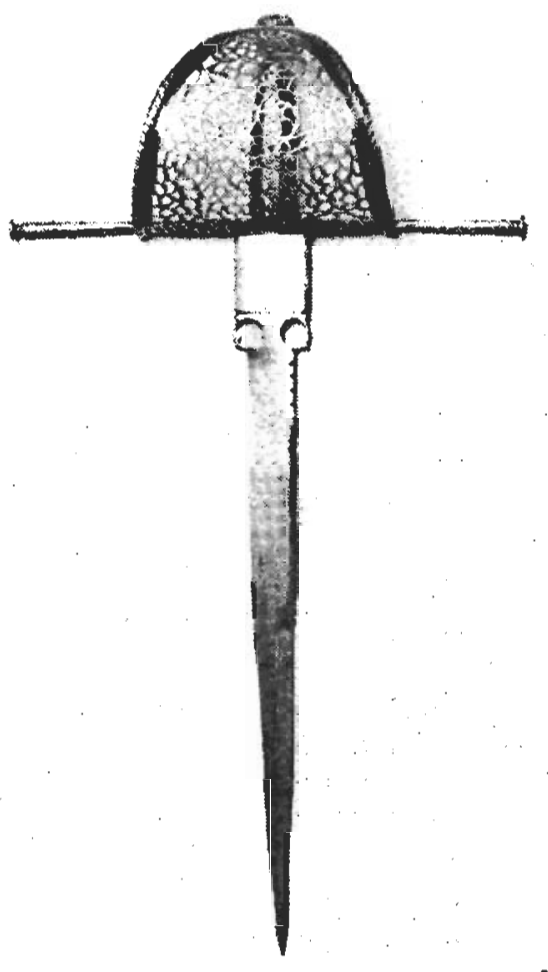

Fotografía N. ${ }^{\circ} 31$. Daga de mano izquierda, española, con reborde labrado de refuerzo en vez de rompepuntas. Marcas no identificadas (véase fotografía de detalle de marca en recazo y gavilán). Colección particular. Mediados del siglo xviI. 


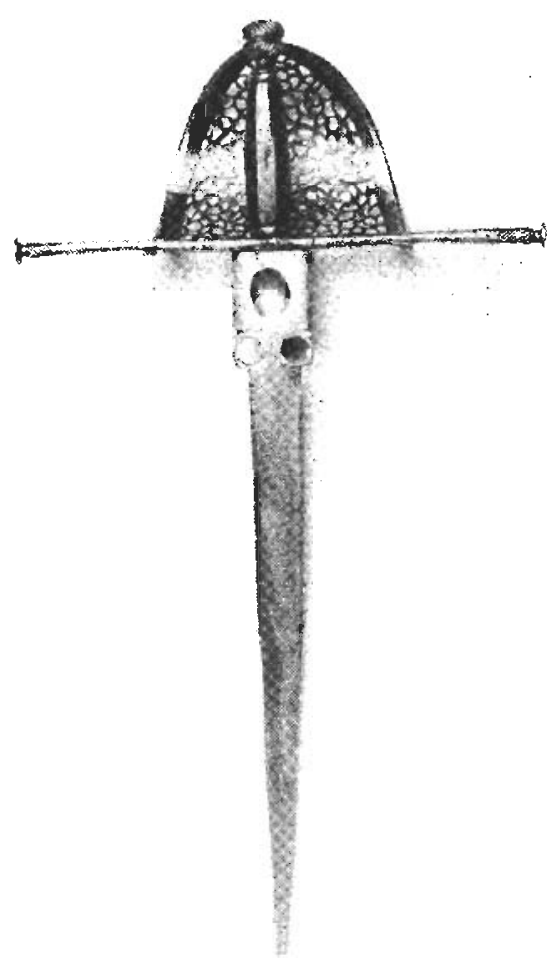

Fotografía N. ${ }^{\circ} 32$. Dorso de la daga anterior, en que se observa el puño de madera exótica, con gajos separados por pequeñas láminas de madreperla.

Fotografía N. 33. Marca en el gavilán te la daga anterior. ¿Pedro de Orozco? Colección particular.

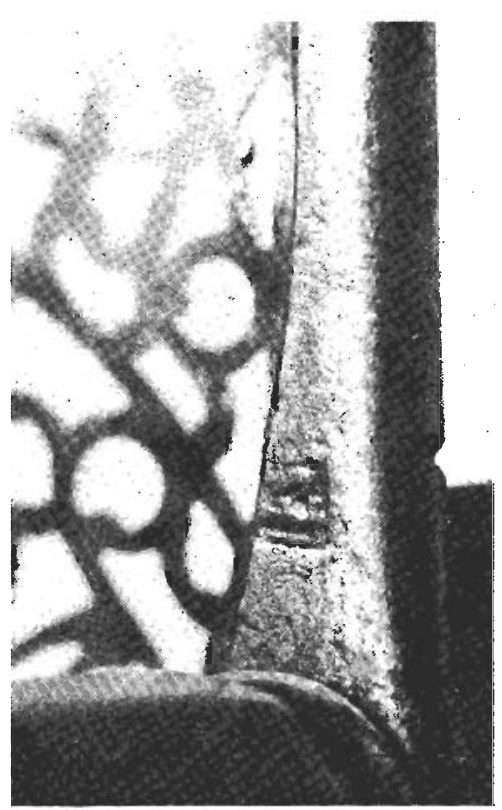




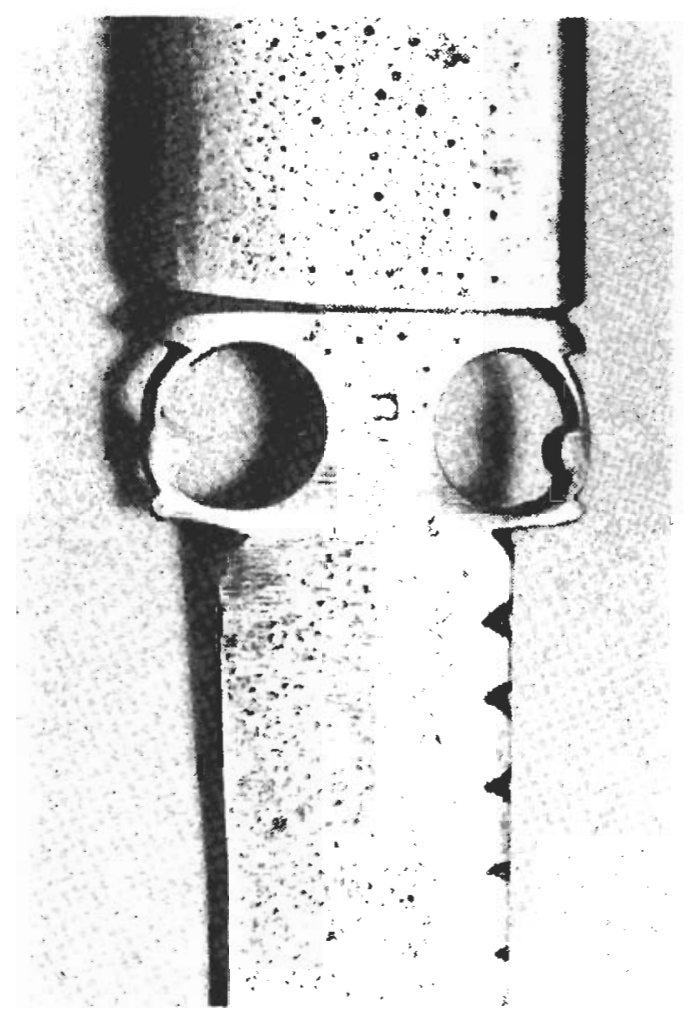

Fotografía N. ${ }^{\circ}$ 34. Marca en el recazo de la daga de la fotografía n. 32 . 


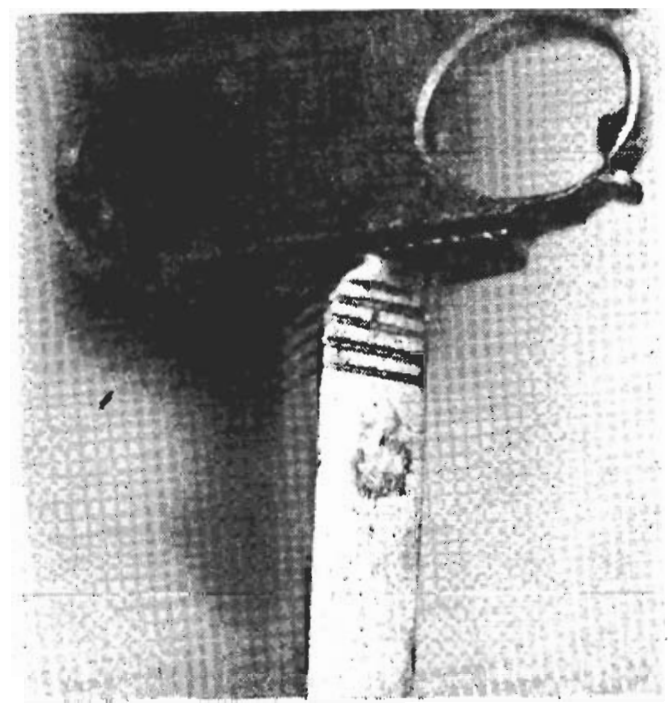

Fotografín N. 35. Marca no identificada en la hoja de la daga de la fotografía n." 28.

Fotografía N.0 36. Inscripción en el canal central de la hoja de la espada reseñada en la fotografía n. ${ }^{\circ}$ 10. ¿ANTONIO ROdRíGuez?

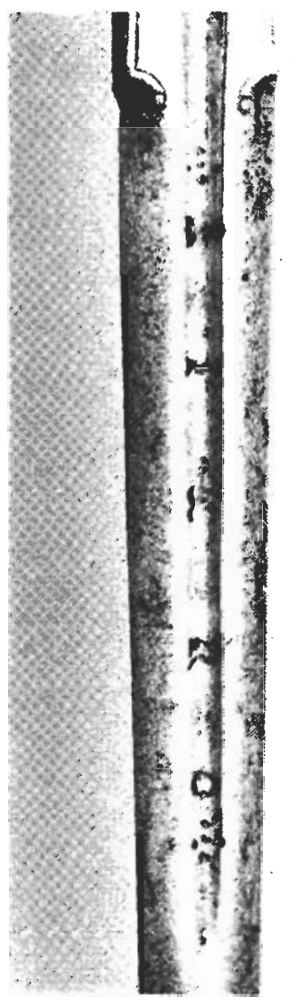




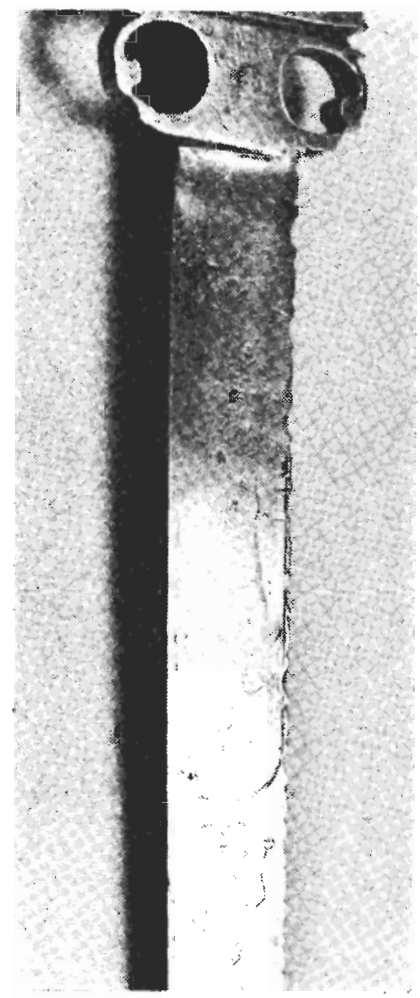

Fotografía n. ${ }^{\circ} 37$. Detalle de grabados, marcas y dibujo en la daga de la fotografía n.: 29.

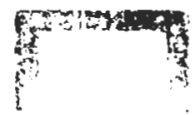

Fotografía N. 38. Inscripción de la hoja de la espada descrita en la fotografía n. 7.

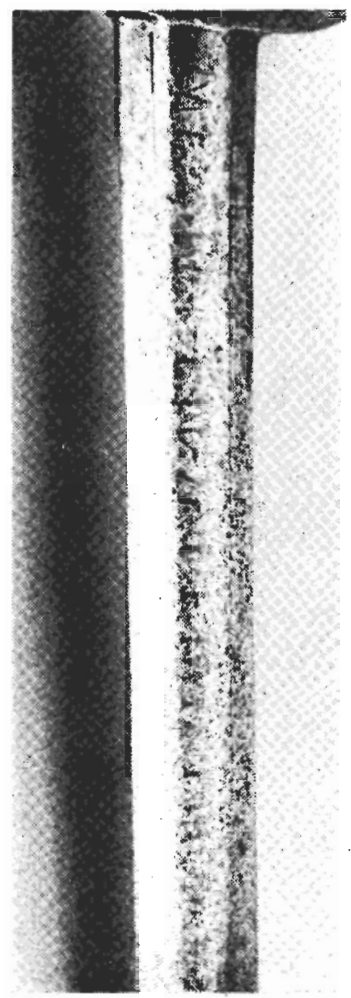

Nora: Las fotografías números 2, 3, 4, 5, 6, 9, 12, 13, 14, 15, 17, 18, 21 у 22 proceden del antiguo catálogo de 1896, de la dispersa colección Estruch.

Mi agradecimiento a D. Eduardo Jiménez por su paciencia en la interprctación y ejecución de los dibujos y a D. ENRIQue Touriño por su labor de fotografía. 